\title{
En la España Medieval
}

ISSN: 0214-3038

http://dx.doi.org/10.5209/ELEM.60010

\section{Capital relacional y capital social en el acceso de la alta nobleza al go- bierno municipal burgalés a principios del siglo XVI: la provisión de la alcaldía mayor a Francisco de Brizuela ${ }^{1}$}

\author{
Alicia Inés Montero Málaga²
}

Recibido: 04 de diciembre de 2017 / Aceptado: 05 de febrero de 2018

Resumen. Este trabajo tiene como propósito examinar los mecanismos ejecutados por la nobleza con el objetivo de insertar a sus servidores dentro de los gobiernos urbanos. Para ello, se tomará como ejemplo el acceso en 1516 de Francisco de Brizuela, contador de la casa de Velasco, a una alcaldía en Burgos. De este modo, se analizará el recurso al capital económico, frecuentemente empleado por la nobleza a través de la compraventa de oficios, pero sobre todo el capital relacional movilizado por este grupo social para tal fin.

Palabras clave: Capital social; capital relacional; clientelismo; nobleza; ciudad.

\section{[en] Relational and Social Capital in the Access of the High Nobility to the Burgos Urban Governments: The Access of Francisco de Brizuela to the Mayor's Office}

\begin{abstract}
The aim of this paper is to examine the mechanisms used by the nobility to insert their servants inside the urban governments. For that purpose, we will take as an example the access of Francisco de Brizuela, accountant of the house of Velasco, to the mayor's office in Burgos. In this way, this paper analyses the use of economical capital, that was often been used by the nobility through the buying and selling of offices, but, above all, the mobilization of relational capital by this group social with this objective.
\end{abstract}

Keywords: Social Capital; Relational Capital; Clientelism; Nobility; City.

Sumario: 1. Introducción. 2. Consideraciones iniciales acerca del nombramiento de alcaldes mayores en la ciudad de Burgos. La proyección de la casa de Velasco sobre los oficios municipales de Burgos. 3. Estrategias desarrolladas en el acceso de Brizuela a la alcaldía. La disposición de un amplio capital relacional. 4. A modo de conclusión. 5. Bibliografía.

Cómo citar: Montero Málaga, A. I. (2018) Capital relacional y capital social en el acceso de la alta nobleza al gobierno municipal burgalés a principios del siglo XVI: la provisión de la alcaldía mayor a Francisco de Brizuela, en En la España Medieval, 41, 227-256.

\footnotetext{
Este trabajo se ha realizado en el marco del proyecto de investigación Ciudad y nobleza en el tránsito a la Modernidad: autoritarismo regio, pactismo y conflictividad politica. Castilla, de Isabel I a las Comunidades (ref. HAR2017-83542-P, Ministerio de Economía, Industria y Competitividad/Agencia Estatal de Investigación/ Fondo Europeo de Desarrollo Regional).

2 Universidad Autónoma de Madrid aliciaines.montero@gmail.com
} 


\section{Introducción}

El 16 de febrero de 1516 accedía al cargo de alcalde mayor de la ciudad realenga de Burgos Francisco de Brizuela (1490-1551), contador mayor de Íñigo Fernández de Velasco (1462-1528), VIII condestable de Castilla, II duque de Frías y IV conde de Haro $^{3}$. Se trata de uno de los muchos ejemplos que entre mediados del siglo XV y principios del XVI pueden documentarse en relación con el desempeño de oficios municipales en el realengo por parte de los criados y clientes de la alta nobleza castellana.

La participación política de la alta nobleza en los concejos castellanos durante la Baja Edad Media a través del recurso a sus clientelas ha sido un procedimiento que se ha registrado para la mayoría de las ciudades de realengo. Con el objetivo de insertarse en los gobiernos municipales y de participar en la toma de decisiones urbanas, los nobles recurrieron, no solo al establecimiento de vínculos clientelares con las élites urbanas, sino también a la promoción de sus servidores dentro de las instituciones municipales, que de manera indirecta les garantizaba el acceso a los espacios urbanos de participación política. Este tipo de prácticas adquieren una relevancia mayor en aquellos concejos en los que los miembros de la alta nobleza no pudieron acceder fácilmente a la ocupación directa de oficios municipales. Una situación especialmente común en las ciudades de la Castilla septentrional al norte de la Meseta, en las que la nobleza debió recurrir a estas "injerencias bastardas", calificativo con que denominó José María Monsalvo Antón a estos mecanismos indirectos de participación política de la nobleza, que no siempre fueron legítimos ${ }^{4}$.

Entre las ciudades en las que se documentan este tipo de prácticas se encuentra Segovia. En esta urbe, tanto los marqueses de Villena como los de Moya mantenían vínculos clientelares con ciertos oficiales del regimiento ${ }^{5}$. También se constata esta situación en León a través del regidor Ramírez de la Llama, lugarteniente del adelantado mayor Pedro Suárez de Quiñones. Caso similar ocurre con Álvaro Garavito en 1468 , regidor del concejo y merino del conde de Luna ${ }^{6}$. Igualmente, en Santander varios miembros de las familias de la élite urbana como los Calleja se encontraban vinculados con los Vega Mendoza, mientras que los Camargo, Escalante o Arce lo hacían con la casa de Velasco ${ }^{7}$, familia esta última que también estuvo presente en el territorio de Vizcaya, donde dispuso de una amplia red clientelar ${ }^{8}$. De otro lado, en Oviedo, los Quiñones o los Quirós tuvieron a finales de la Edad Media influencia en la vida política urbana9. En Valladolid, el conde de Benavente disponía de

La bibliografía referente a esta casa señorial es abundante, algunos trabajos y autores de referencia son: Franco Silva, Entre los reinados; Idem, "El gobierno y la administración"; Idem, "Notas sobre la capilla"; Idem, "El reparto de los bienes"; González Crespo, Elevación de un linaje; Jular Pérez-Alfaro, "Dominios señoriales"; Idem, "Nobleza y clientelas"; Idem, "Porque tengo obligación"; Idem, "Los solares"; Idem, "La importancia de ser"; Moreno Ollero, Los dominios señoriales; Paulino Montero, El patrocino arquitectónico; Preyra Alza, El señorio de los Condestables.

4 Monsalvo Antón, "La sociedad política", p. 393.

Asenjo González, Segovia: la ciudad y su tierra, p. 350.

Álvarez Álvarez, “Oficiales y funcionarios concejiles”, pp. 45-65.

Solórzano Telechea, Santander en la Edad Media, pp. 287-288.

8 Además de los trabajos mencionados en la nota 14, a propósito de la presencia de la nobleza en el territorio vasco, en relación con la casa de Velasco y su intervención en Vizcaya, véase Dacosta Martínez, Los linajes de Bizkaia, pp. 127-143.

9 Álvarez Fernández, "La ciudad de Oviedo", pp. 557-559. 
criados dentro del regimiento ${ }^{10}$. Asimismo, en Salamanca, el duque de Alba situó a varios de sus partidarios dentro del concejo, logrando incluso que en 1494 un oficio tan destacado como el de regidor le fuese reservado para uno de sus servidores por los Reyes Católicos, sin que previamente lo hubiese solicitado ${ }^{11}$. Por su parte, tanto los condes de Medinaceli como los señores de Almazán o de Cameros mantenían a miembros de sus clientelas dentro del concejo de Soria, caso de Pedro de Mendoza, IV señor de Almazán, que a mediados del siglo XV contaba con varios regidores entre sus acostados ${ }^{12}$. Por último, dentro de la Submeseta Sur, en Cuenca son varios los ejemplos relativos a la colocación de clientes por parte de los nobles en el gobierno urbano, especialmente en lo que respecta al linaje de los Hurtado de Mendoza. Así se constata en 1440, cuando Diego Hurtado de Mendoza, señor de Cañete, lograba la aprobación de Fernando Alonso de Guadalajara como regidor ${ }^{13}$.

Además de estos ejemplos, no debe obviarse la participación directa de los propios nobles en los gobiernos municipales a través de la ocupación de oficios de diversa índole, generalmente de cargos extraconcejiles como las alcaidías o corregidurías, si bien en ocasiones se los puede observar desempeñando oficios de primer orden en el proceso político-decisional urbano, como las alcaldías o las regidurías. Situación que muy particularmente se constata en el territorio andaluz, en ciudades como Córdoba o Sevilla, núcleos en los que a finales de la Edad Media la alta y mediana nobleza constituía un importante porcentaje dentro de la élite urbana, además de contar con extensas redes clientelares dentro de estas ciudades. Pero también en el resto de las ciudades del realengo, de tal modo que es posible vincular a cada una de ellas con uno o varios linajes de la alta nobleza: Guadalajara con los Mendoza, mediante el desempeño de alcaldías y alguacilazgos; Salamanca con los Alba; Cuenca con los Hurtado de Mendoza, presentes sobre todo a través de la ocupación del cargo de guarda mayor, oficio exclusivo de las ciudades de Cuenca, Huete, Iniesta y Alarcón; León con el conde de Luna a través de sus criados; Toledo con los Ayala o los Silva; Córdoba con los Fernández de Córdoba presentes en las regidurías, al igual que Sevilla con los Enríquez o los Guzmán; o Segovia con los Cabrera o los Pacheco $^{14}$.

Sin embargo, a pesar del cada vez mayor conocimiento que se tiene sobre la presencia de la alta y mediana nobleza en el realengo castellano, puede convenirse que apenas se ha reparado en lo que se refiere a la inserción de las clientelas señoriales en las estructuras municipales de poder. Más allá de la identificación del vínculo que

\footnotetext{
Martín Romera, Las redes sociales, pp. 420-421, 496-498; Ruquoi, Valladolid en la Edad Media, pp. 53-69.

Monsalvo Antón, “Torres, tierras, linajes”, p. 199.

Diago Hernando, "La proyección de las casas", p. 869.

3 Jara Fuente, "La nobilización de un concejo", p. 1032. También: Ortega Cervigón, "Lazos clientelares y bandos nobiliarios" e Idem, "Por servicios muchos".

14 Resulta imposible recoger aquí la multitud de trabajos que, de un modo u otro, se han referido a la presencia de la alta nobleza en las ciudades castellanas. Entre los más destacados puede citarse a: Cabrera Sánchez, Nobleza, oligarquía y poder; Collantes de Terán, Sevilla en la Baja Edad Media; Diago Hernando, "La participación de la nobleza"; Idem, "La proyección de las casas"; Idem, "Intervencionismo de la alta nobleza"; Díaz de Durana, La lucha de bandos; Díaz de Durana y Fernández Larrea, "Las relaciones contractuales"; Idem, "Las villas cantábricas"; García Fernández, "Teorías y práxis"; Jara Fuente, "La nobilización de un concejo"; Idem, "Didáctica de las relaciones"; Idem, "Disciplinando las relaciones"; Ladero Quesada, Andalucía en el siglo XV; Layna, Historia de Guadalajara; Monsalvo Antón, "La sociedad política”; Ortega Cervigón, "El intrusismo nobiliario"; Idem, "Lazos clientelares y bandos nobiliarios"; Idem, "Por serviçios muchos"; Idem, "Ciudad, nobleza y frontera"; Palencia Herrejón, Los Ayala de Toledo; Quintanilla Raso, "El dominio de las ciudades"; Idem, "Estructura y función de los bandos nobiliarios"; Idem, "Principios y estrategias de la cultura nobiliaria"; Sánchez Benito, "Nobleza territorial y política ciudadana"; Sánchez Saus, La nobleza andaluza.
} 
une a un oficial concejil con un noble determinado, los investigadores rara vez han profundizado en el examen de las estrategias y mecanismos que habrían sido desarrollados por los nobles de cara a promover el acceso de los suyos a los diversos cargos municipales. Las ocasiones en las que se ha incidido en esta cuestión, se ha priorizado la parte más formal del proceso de acceso a los oficios concejiles, atendiendo especialmente a la tipología de nombramiento (concejil o regio) y a los documentos legales que lo rodean (cartas de expectativa, privilegios de renuncia, etcétera) ${ }^{15}$. No obstante, como tendremos ocasión de examinar mediante el ejemplo de Francisco de Brizuela, en ciudades como Burgos, la designación de alcaldes o regidores respondía a un complejo proceso en el que fue necesario el concurso de una mayoría suficiente de oficiales municipales con facultad de voz y voto en las sesiones de ayuntamiento, que en último término, en el momento de su aceptación por parte de la institución concejil, se encontrasen a favor de la aprobación de la carta regia de expectativa de oficio o del traspaso del cargo correspondiente ${ }^{16}$.

Dentro de este proceso, la nobleza debió ejecutar todo un conjunto de prácticas destinadas a lograr la aceptación de sus candidatos, a pesar de que estas incumplían la mayoría de las veces la normativa referente a la designación de oficios concejiles. Con esa finalidad, los nobles recurrieron a la movilización de variados recursos, no solo de tipo económico, bien documentados en las compras de oficios -opción a la que frecuentemente acuden los nobles-, sino sobre todo a su capital relacional. Entendido este capital relacional como la suma de relaciones que un individuo es capaz de movilizar dentro de la red social en la que participa, que es reconstruida por el historiador para explicar dichas relaciones. Dentro de este marco debe considerarse además que, a mejor posición y capacidad de movilización de recursos por parte de los individuos con los que se establece relación, mayor es el valor del capital relacional $^{17}$. De este modo, gracias a los contactos que los nobles fueron capaces de movilizar dentro de la red social que tejieron en un determinado municipio con alcaldes y regidores, pudieron contar con los votos favorables necesarios para la aprobación de sus oficiales. Al respecto de esta cuestión, en la medida en la que la obtención de un oficio municipal dependió de los apoyos obtenidos en una red social determinada,

15 Sin duda, la mayor excepción la representan los trabajos de José María Monsalvo Antón, si bien se plantean sobre un concejo señorial y no de realengo. Principalmente, por abordar de manera específica la designación de alcaldes, como se muestra en Monsalvo Antón, "El reclutamiento del personal”, pp. 173-195. Véase además Idem, El sistema político concejil; Idem, "Gobierno municipal, poderes urbanos”, pp. 409-448. Por su parte, dentro del realengo, aunque no se aborda particularmente la relación de los oficiales concejiles con la nobleza, las diferentes estrategias de acceso a los oficios municipales han sido examinadas para el caso conquense por Jara Fuente, Concejo, poder y élites.

16 Esta cuestión ya ha sido planteada con acierto por José Antonio Jara Fuente. Al interrogarse por el acceso a los oficios concejiles conquense, este autor señalaba cómo habrían accedido a sus cargos los oficiales municipales conquenses, indicando cómo "la pregunta no hace referencia, a los aspectos más formales de la incorporación al regimiento (cartas de expectativa y traspasos de oficios) sino a los mecanismos que se han puesto en ejecución con ocasión del ingreso o de la inadmisión de aquellos otros que procuraron incorporarse al mismo sin existo. Al fin, lo importante no es tanto quién ingresa sino el proceso que conduce a su acceso a la regiduría", Jara Fuente, Concejo, poder y élites, p. 109.

17 La noción de capital relacional se ha desarrollado fundamentalmente en el ámbito de las ciencias empresariales desde finales del siglo XX, especialmente a raíz de los trabajos de Edvinsson y Malone, que integran este concepto dentro del "capital intelectual"; Edvinsson y Malone, Intellectual Capital. Sin embargo, han sido ya varios los autores españoles que han incorporado este concepto a sus estudios históricos. En este sentido, quizás el ejemplo más representativo sea el modernista José María Imízcoz, si bien para el periodo medieval se ha aplicado también con notable éxito al estudio de las élites urbanas o financieras (Imízcoz Beunza, "El capital relacional”, pp. 227-282; Martín Romera, Las redes sociales de la oligarquí; Ortego Rico, Poder financiero y gestión tributaria). 
la posición alcanzada por estos oficiales debe ser considerada, asimismo, en términos de capital social, como tendremos ocasión de comprobar a través de la alcaldía de Brizuela ${ }^{18}$.

Por consiguiente, en este marco, el ejemplo de Brizuela resulta ser una buena plataforma desde la que analizar los recursos económicos o sociales de los que la nobleza dispuso de cara a lograr el acceso de los miembros de sus casas señoriales a los oficios municipales del realengo. Este tipo de prácticas, ejecutadas por la nobleza con el objetivo de insertarse en el gobierno urbano, adquieren especial relevancia dentro del marco espacial y socio-jurídico que representa la ciudad de Burgos, si se tiene presente que, en la Caput Castellae, tanto los poderosos como los que "vivían con" ellos, tuvieron vetado el acceso directo a los oficios municipales. Por ello, el objetivo de las páginas que siguen es examinar la estrategia desarrollada por los condestables de Castilla con el fin de alcanzar la promoción de su contador mayor en el concejo burgalés. Un proceso que no puede limitarse al estudio del privilegio regio que Brizuela habría obtenido de la reina Juana I autorizando la renuncia que, en su nombre, habría hecho del oficio el alcalde anterior, Francisco de Lerma. De igual modo, no puede circunscribirse al examen de la venalidad del cargo que esta renuncia parece encubrir, sino que es necesario analizar los mecanismos arbitrados por los condestables para lograr el éxito de su contador, que fueron desde la elección del oficial mejor posicionado para su promoción dentro del concejo, hasta el control de los votos necesarios que su aprobación como alcalde requería.

En este sentido, este estudio de caso pretende servir de modelo comparativo desde el que examinar algunos de los procesos similares que se han observado en otros núcleos del realengo castellano. Por este motivo, a continuación comenzaremos examinando algunas particularidades acerca del procedimiento de designación de alcaldes en Burgos, sus requisitos y normativa, comparando el caso de Brizuela con otros semejantes que se observan para la casa de Velasco, así como con lo sucedido en otros núcleos del realengo. En último término, el examen del proceso de entrada de Francisco de Brizuela a un oficio municipal en Burgos va a servirnos de hilo conductor para profundizar en el estudio de las relaciones ciudad-nobleza. Se trata de un modelo de penetración de los nobles en el realengo que, en cierto modo, puede ser calificado de pacífico, frente a otro tipo de injerencias nobiliarias, en las que los nobles optarían por la usurpación de recursos o jurisdicción a las ciudades ${ }^{19}$, si bien no siempre estos intentos de mediación indirecta de los nobles en los gobiernos municipales se produjeron ajenos al conflicto, ya que fueron varias las voces que en cada momento se levantaron en contra de este tipo de intromisiones.

18 Bourdieu, "Le capital social", pp. 2-3; "The Forms of Capital", pp. 241-258.

19 Sirvan de ejemplo: Cabrera Muñoz, "Usurpación de tierras", II, pp. 33-112; Jara Fuente, "Haciendo frente a las depredaciones", pp. 280-299; Monsalvo Antón, "Usurpaciones de comunales", pp. 81-121; Muñoz Gómez, "Conflictos de límites", pp. 209-223; Ortega Cervigón, "Usurpaciones de términos", pp. 221-238; Sánchez Benito, "Territorio y conflicto", pp. 89-118. 


\section{Consideraciones iniciales acerca del nombramiento de alcaldes mayores en la ciudad de Burgos. La proyección de la casa de Velasco sobre los oficios munici- pales de Burgos}

Entre 1470 y 1500 aproximadamente, Pedro Fernández de Velasco, VI condestable de Castilla y II conde de Haro, y su esposa, Mencía de Mendoza, desarrollaron un proceso de "recentralización" de su señorío por el que la ciudad de Burgos pasó a ser, no solo el nuevo centro simbólico del señorío, expresado principalmente a través de la capilla de la Purificación que ambos edificaron en la catedral de Burgos y en la que se mandaron enterrar ${ }^{20}$, sino también el nuevo centro político-administrativo. La construcción durante esta etapa del palacio del Cordón en el centro de la ciudad fijó, a partir de ese momento, la residencia semipermanente de los titulares del linaje en la ciudad, primero de Pedro Fernández de Velasco y Mencía de Mendoza y, posteriormente, de sus hijos Bernardino e Íñigo Fernández de Velasco. Con su traslado a Burgos, los sucesivos condestables de Castilla se hicieron acompañar de sus servidores, así como de los oficiales más destacados de la administración de su señorío ${ }^{21}$.

De este modo, en este periodo, pero sobre todo durante las jefaturas de Bernardino Fernández de Velasco (1492-1512) e Íñigo Fernández de Velasco (1512-152022), es posible comprobar cómo los condestables residieron en la ciudad junto con sus criados y allegados ${ }^{23}$, algunos de los cuales solicitaron al concejo la aceptación de su condición de vecinos, así como la concesión de una carta de vecindad. En muchos casos, el interés por su reconocimiento formal como vecinos de la ciudad respondía a una estrategia para ser designados en un oficio municipal. Así lo demuestra el hecho de que, en ocasiones, estos oficiales habrían solicitado al concejo el avecindamiento tan solo unos días antes de presentar una carta de provisión de oficio, que habrían adquirido con anterioridad, y cuya aprobación por parte del concejo requería previamente su reconocimiento como vecinos. En este sentido, Brizuela fue uno más de los oficiales señoriales que a principios del siglo XVI se trasladaron a vivir a Burgos cuando, al fallecer Bernardino Fernández de Velasco sin descendencia masculina, la titularidad del linaje recayó en su hermano Íñigo. Francisco se habría trasladado a Burgos desde Berlanga del Duero, villa de la que era originario y en la que se encontraba sirviendo a María de Tovar, esposa de Íñigo Fernández de Velasco. Es posible

20 Acerca de la concepción que ambos cónyuges tenían acerca de su etapa al frente del señorío, especialmente en relación con el nuevo periodo que abre para la historia del linaje la construcción de la capilla de la Purificación, en la que ambos se entierran, rompiendo con lo que hasta ese momento había sido la trayectoria de los titulares del linaje, véase: Pereda y Rodríguez de Ceballos, "Coeli enarrant gloriam Dei", pp. 17-34; Pereda, "Mencía de Mendoza", pp. 9-119; Paulino Montero, El patrocinio arquitectónico, pp. 366-367. Esta última autora ha propuesto el término de "recentralización", que aquí suscribimos, para explicar este cambio de intereses en la dinámica señorial en torno a Burgos (Paulino Montero, El patrocinio arquitectónico, pp. 124, 279, 433).

21 Esta cuestión aparece claramente recogida para el año de 1514, cuando se anota que, "el sennor condestable e la sennora duquesa que vienen a asentar en esta ciudad e [...] residen con la sennora duquesa sus alcaldes mayores", Archivo Municipal de Burgos (en adelante AMB), Libros de Actas (en adelante LLAA), 1514, f. 170rv.

22 Aunque Íñigo Fernández de Velasco fallece en 1528, a partir del año 1520, tras los sucesos de las Comunidades, es posible comprobar cómo la presencia del linaje en Burgos empieza a declinar en favor de otras villas, como Berlanga del Duero o Pedraza en Segovia (Alegre Carvajal, "Prestigio, ciudad y territorio", pp. 14-15; Franco Silva, "Pedraza de la Sierra", pp. 97-142).

23 En varias ocasiones las actas municipales burgalesas dan noticia de la presencia en Burgos de los miembros de la casa del condestable, normalmente con motivo de los problemas que estos solían causar en la ciudad. Así se observa, por ejemplo, en: AMB, LLAA, 1516, ff. 63v-64v. También han dejado constancia de cómo, además, los condestables tenían allegados entre los vecinos de la ciudad (AMB, LLAA, 1513, f. 138v). 
que este traslado hubiese sido promovido por el condestable, quien debió considerar a este contador señorial como el candidato idóneo, no solo para promocionar dentro de la casa señorial, sino también para ocupar un oficio municipal en la ciudad de Burgos. Así, en 1516, tras haber adquirido una carta de vecindad, Francisco de Brizuela lograba acceder a uno de los oficios centrales de la gobernación municipal: una alcaldía.

Durante la Baja Edad Media, solían ser seis los alcaldes que integraban la planta del gobierno municipal en la ciudad de Burgos, a la que deberían sumarse dieciséis regidores, un escribano mayor, un merino y dos procuradores mayores, representantes estos últimos de las vecindades en las reuniones de ayuntamiento. Regidores y alcaldes componían la cúspide del poder en la ciudad, fundamentalmente porque se trataba de los dos únicos oficios con facultad de voz y voto en las sesiones de ayuntamiento y, por tanto, aquellos en los que en último término descansaba todo el proceso de decisión política ${ }^{24}$. Si bien las alcaldías son cuantitativa y cualitativamente inferiores a las regidurías, no solo porque el concejo contaba con seis alcaldes frente a un total de dieciséis regidores, sino también porque parecía asociarse una mayor dignidad a la ocupación de las regidurías, en la práctica, lo cierto es que sus competencias y atribuciones fueron semejantes, por lo que en la mayoría de las ocasiones estos veintidós oficiales actuaron en bloque ${ }^{25}$.

A finales del siglo XV y comienzos del siglo XVI, para que un individuo pudiese acceder a una alcaldía en Burgos debía cumplir varios requisitos, la mayoría comunes a otras ciudades castellanas ${ }^{26}$. En primer lugar, el candidato debía poseer carta de vecindad, es decir, obtener mediante la vía contractual el reconocimiento explícito de su condición de vecino por parte del concejo burgalés. Entre las obligaciones específicas que el contrato de avecindamiento estipulaba, se dispone que el solicitante debía estar en posesión de un domicilio en la ciudad, residencia en la que acuerda establecerse durante un número de años determinado. Además, en algunos casos, se requiere al solicitante el compromiso del pago de impuestos, por lo que en ocasiones este último se acompañó de fiadores que avalaban la ejecución de este requisito ${ }^{27}$.

Aunque aparentemente se trata de unas obligaciones de fácil cumplimiento, no todos los vecinos de Burgos dispusieron de una carta de vecindad, que con cierta fre-

24 Entre 1492 y 1517 el escribano mayor Gonzalo de Cartagena debió tener facultad de voz y voto. Así nos lo hace saber una ordenanza de la reina Juana I de 1508 (AMB, Sección Histórica (en adelante HI), 4820). Pero también algunas de las actas municipales de la ciudad, en las que claramente se ve a este escribano ejerciendo el derecho al voto (AMB, LLAA, 1514, ff. 85v-86r). Por consiguiente, en 1516, año de la provisión de Francisco de Brizuela, el escribano mayor tendría facultad para votar su recibimiento como alcalde, según tendremos ocasión de examinar en las páginas siguientes.

25 Así lo ha demostrado Guerrero Navarrete, Organización y gobierno en Burgos, pp. 96-100. Sobre las fórmulas de transmisión del poder en Burgos y la configuración del sistema oligárquico, véase Guerrero Navarrete, "Fórmulas de transmisión del poder", pp. 173-183.

26 Acerca de los mecanismos generales de acceso a los oficios, requisitos y sistemas de nombramiento, véase García Marín, El oficio público en Castilla, pp. 137-167 y Álvarez Álvarez, "Oficiales y funcionarios concejiles". Asimismo, en relación con las plataformas de transmisión del poder resulta interesante el trabajo de Álvarez Fernández, "Por ser hombre". De otro lado, el territorio vasco representa un espacio interesante en lo que respecta al acceso electivo a los oficios, que puede servir de comparativa para lo documentado en la ciudad del Arlanzón. En este sentido, conviene señalar fundamentalmente el trabajo García Fernández, Gobernar la ciudad, pp. 246-278. Para el caso particular de Burgos, los requisitos y procedimiento de elección a los que vamos a referirnos a lo largo de las siguientes páginas pueden encontrarse en: Bonachía Hernando, El concejo de Burgos, pp. 79-86; Guerrero Navarrete, Organización y gobierno en Burgos, pp. 96-100; Jones Mathers, "Cómo llegar a ser regidor. Primera parte", pp. 327-335.

27 Bonachía Hernando, El concejo de Burgos, p. 45. 
cuencia fueron revocadas, especialmente si se tenía constancia de que un vecino ya no mantenía su residencia habitual en la ciudad. Al respecto de esta cuestión, llama la atención la afirmación que en 1529 realizaba el regidor Pedro Orense de Covarrubias, señalando cómo, de entre los seis mil vecinos que en ese momento tenía la ciudad, tan solo un total de cien poseían carta de vecindad; hecho que podría indicar una cierta dificultad en el proceso de obtención de la misma ${ }^{28}$. No obstante, resulta difícil establecer el número total de los individuos avecindados en el siglo $\mathrm{XV}$, sin que ni siquiera, de hecho, sea posible determinar la población absoluta de la ciudad durante esta centuria, que tradicionalmente se ha establecido en torno a unos diez mil habitantes ${ }^{29}$.

En cualquier caso, en lo que respecta a la casa de Velasco, de manera general se comprueba cómo todos los domésticos y oficiales de la administración del señorío de los sucesivos condes de Haro que desearon avecindarse en la urbe entre finales del siglo XV y principios el siglo XVI pudieron adquirir carta de vecindad sin relativos inconvenientes. Así, por ejemplo, en 1480, el bachiller Villalpando, alcalde mayor de Pedro Fernández de Velasco, VI condestable de Castilla y II conde de Haro, obtenía del concejo el estatuto de vecino, tras haber expuesto su deseo de mudarse a la ciudad para residir con su señor ${ }^{30}$. De igual manera le fue concedido en julio de 1517 a Juan de Zumel, consejero y criado de Íñigo Fernández de Velasco, VIII condestable de Castilla y II duque de Frías ${ }^{31}$. Por último, en lo que se refiere a Francisco de Brizuela, el 14 de febrero de 1516 obtenía sin aparentes contradicciones la carta de vecindad para él y su camarero, Sarabia ${ }^{32}$. A pesar de ello, como tendremos ocasión de examinar en las páginas siguientes, su condición de vecino sería discutida dos días después de haber obtenido la carta de vecindad. Similar ejemplo había sucedido años antes cuando en 1505, en el momento de ser aprobado como regidor de la ciudad, se discutía la vecindad de Fernando de Bañuelos, secretario del II conde de Haro y mayordomo de su hijo Bernardino Fernández de Velasco. En este caso, parecían existir ciertas dudas acerca de si Bañuelos cumplía el requisito relativo a la residencia en la urbe. Este asunto fue rápidamente solventado, ya que Bañuelos habría tenido la precaución de recurrir a los servicios de un escribano público, Juan López, quien junto con el regidor Andrés de Ribera atestiguó la posesión por parte de este oficial señorial de casa pertrecha en la ciudad ${ }^{33}$.

El aspecto que interesa destacar aquí es cómo el avecindamiento de estos miembros de la clientela del condestable en Burgos no generó en un principio oposición alguna por parte del regimiento, como si lo hace su inserción en la institución concejil, según se infiere de los casos de Fernando de Bañuelos y Francisco de Brizuela, que más adelante analizaremos. Dentro de este marco, cabe decir que una vez ave-

\footnotetext{
Jones Mathers, "Cómo llegar a ser regidor. Primera parte", p. 327.

Bonachía Hernando, El concejo de Burgos, pp. 43-44.

AMB, LLAA, 1480, f. 24r.

AMB, LLAA, 1515, f. 113r.

32 En la misma petición aparece: "Brizuela contador del condestable e Sarabia su camarero", AMB, LLAA, 1516, f. 57r. La ambigüedad de la frase nos impide determinar con exactitud si Sarabia sería camarero del condestable o del propio Brizuela, opción esta última más probable, puesto que Brizuela se encontraba casado con Ana de Sarabia, pudiendo ser este camarero familia de su esposa. Por otra parte, no hemos documentado a ningún camarero de la casa de Velasco que responda a esa denominación, aunque sí aparecen mencionados en la documentación familiar un paje y un sillero denominado Sarabia (Archivo Histórico Nacional (en adelante AHN), Nobleza, Frías, c. 93, d. 1-7, ff. 35-36).

33 AMB, LLAA, 1505, ff. 36v-39r.
} 
cindados, algunas de las actividades que estos oficiales señoriales llevaron a cabo en la ciudad al servicio de los condestables también plantearon ciertos problemas al concejo. Concretamente, en 1506 se denunciaba cómo los alcaldes mayores de Bernardino Fernández de Velasco, que se habían traslado a vivir con este último a Burgos, atendían en la ciudad los pleitos de las villas del señorío del condestable, contradiciendo la jurisdicción real ${ }^{34}$.

Paralelamente, en lo relativo a Francisco de Brizuela y Juan de Zumel, es posible además registrar un elemento común. Ambos habrían solicitado al concejo la concesión del estatuto de vecino unos días antes de presentar su petición de acceso al oficio municipal, posiblemente ya en posesión del privilegio regio que les facultaba para acceder al cargo, lo que da muestras de una planificada estrategia destinada a lograr su designación como alcaldes que, en primer lugar, pasaba por obtener el estatuto de vecinos ${ }^{35}$. No ocurre así con Fernando de Bañuelos, quien ya debía de llevar residiendo un tiempo en la ciudad antes de que Fernando el Católico le hiciese merced de una regiduría ${ }^{36}$. Sin embargo, también en su caso se puede hablar de una cierta previsión en el acceso y desempeño de su oficio, pues quince días antes de que su provisión a la regiduría fuese aprobada por el concejo burgalés, Bañuelos otorgaba desde Toro, en donde se encontraba acompañando a la corte y al consejo real, poder a Antonio de Melgosa y Gutierre de Mier, tesorero y camarero respectivamente de Bernardino Fernández de Velasco, para presentar la provisión regia del oficio, solicitar su cumplimiento y tomar posesión del cargo en su nombre ${ }^{37}$. Bañuelos preveía así su ausencia de la ciudad, que se prolongó hasta un año después ${ }^{38}$.

El segundo de los requisitos que un individuo debía cumplir para acceder a una alcaldía era ser mayor de dieciséis años. En algunos casos, debido a que frecuentemente las alcaldías y regidurías en Burgos eran ocupadas por la vía de la renuncia, esto es, el oficial saliente renunciaba en el entrante, normalmente su hijo o pariente más cercano (padre, hermano o sobrino) ${ }^{39}$, no siempre se cumplió este requisito. De modo que algunos alcaldes fueron aceptados con una edad menor a la muerte prematura de su pariente ${ }^{40}$. Tampoco podía acceder a un cargo concejil quien fuese cléri$\mathrm{go}^{41}$. Y, finalmente, el requisito que más nos interesa señalar aquí: ningún candidato a un oficio municipal en la ciudad de Burgos podía "vivir con señor", es decir, ser criado, allegado o llevar acostamiento de ningún "señor poderoso, prelado o caballero". Se trata de una normativa común a muchas otras ciudades del realengo castellano, destinada a frenar, no solo el acceso de los miembros de las casas nobiliarias a los concejos, sino también a la clientelización de los oficiales concejiles por parte de la nobleza, sobre todo a través del establecimiento de allegamientos o acostamientos.

AMB, LLAA, 1506, ff. 149r y v.

35 El 14 de febrero de 1516 Brizuela solicitaba carta de vecindad. Dos días más tarde, el 16 de febrero, presentaba su solicitud a la alcaldía ante el concejo (AMB, LLAA, 1516, ff. 57r-58v). Por su parte, Zumel pedía ser reconocido como vecino un 2 de julio y, como alcalde, doce días más tarde (AMB, LLAA, 1517, ff. 113r, 121r).

36 AMB, LLAA, 1505, ff. 36v-39r. También se menciona esta provisión de oficio en: Archivo General de Simancas (en adelante AGS), Cámara de Castilla (en adelante CCA), Cédulas 9, f. 252, d. 7.

37 AMB, LLAA, 1505, f. 40rv.

38 AMB, LLAA, 1506, f. 199v.

39 El proceso de renuncia fue una práctica de transmisión de oficios frecuente en la mayoría de las ciudades castellanas, especialmente en lo que respecta a las regidurías. De manera general, tuvo lugar entre parientes, dando lugar a la hereditariedad y a la patrimonialización de los cargos en manos de determinadas familias (Tomás y Valiente, "Origen bajomedieval de la patrimonialización”).

40 Jones Mathers, "Cómo llegar a ser regidor. Primera parte", pp. 328-329.

41 Jones Mathers, "Cómo llegar a ser regidor. Primera parte", p. 330. 
En este sentido, fueron varias las quejas que, con motivo de esta cuestión, se presentaron en cortes por parte de los procuradores de las ciudades, caso de las Cortes de Valladolid de 1447, en las que se solicitaba que las regidurías no sean otorgadas a personas poderosas:

los rregimientos e otros ofiçios que vacaren enlas dichas vuestras çibdades e villas no se den por vacaçion nin rrenunçiaçion a personas poderosasm saluo llanas, e que derechamente ayan de acatar vuestro seruiçio e bien e pro común delas dichas vuestras çibdades e villas, e que asy mismo que mande alos corregidores e alcaldes e alguaziles rregidores e jurados e oficiales vezinos e moradores delas dichas vuestras çibdades e villas, so grandes penas, que non consientan que personas algunas se apoderen dellas sin vuestro especial mandado ${ }^{42}$.

Con anterioridad, ya en las Cortes de Toledo de 1436 o en las de Valladolid de 1442 se había tratado de evitar que los regidores se encontrasen vinculados con los nobles o eclesiásticos, y que aquellos que tuviesen más de doscientos vasallos ocupasen algún oficio municipal ${ }^{43}$. También fue frecuente encontrar estas prohibiciones en las ordenanzas particulares de algunos concejos del realengo, que normalmente fueron desobedecidas. Tal es el ejemplo de lo sucedido en Cuenca en 1441, cuando se prohíbe que los regidores reciban acostamiento de prelado o caballero. Al respecto, resulta significativo que encabezando la ordenanza en la que se incluía dicha prohibición se encontrase el tercer marqués de Cañete, Diego Hurtado de Mendoza, personaje que mantenía diversos vínculos con los oficiales conquenses ${ }^{44}$. Situación similar se produce en Segovia en 1479, año en el que se ordena que los regidores no mantengan acostamiento con ningún señor, especialmente con Andrés Cabrera, Diego Arias Dávila y el obispo Juan Arias. Aunque esto no fue impedimento para que varios de los oficiales municipales siguiesen vinculados a los mismos o para que el propio marqués de Moya llegase a regidor de Segovia en $1511^{45}$.

Sin embargo, otros concejos fueron más estrictos con el cumplimiento de esta norma, como Aranda del Duero. Desde 1480 y hasta la muerte de Isabel I se vigiló estrictamente que los oficiales municipales de esta villa no sirviesen a miembros de la nobleza. No obstante, a partir de 1504 parece constatarse una mayor relajación y flexibilidad en el cumplimiento de este requisito, siendo varios los regidores que a partir de ese momento mantienen vínculos con algunos nobles comarcales, especialmente con el conde de Miranda, como ocurre con Fernando de Covarrubias, regidor de Aranda de Duero y mayordomo de este conde ${ }^{46}$. Asimismo, en lugares como Logroño, la presión ejercida por los concejos logró, no solo frenar este tipo de intromisiones, sino que los propios nobles adquiriesen inmuebles en la urbe y se avecindasen $^{47}$.

\footnotetext{
42 Cortes de los antiguos reinos, pp. 515-156. Además, el rey accedía a que los caballeros y escuderos presentes en estas ciudades no se encontrasen vinculados con ningún otro señor ni recibiesen de ellos tierras, acostamientos o cualquier otro beneficio (Cortes de los antiguos reinos, pp. 519-520).

43 Así lo recoge Monsalvo Antón, 1990: 395.

44 Jara Fuente, "La nobilización de un concejo", p. 1033.

45 Asenjo González, Segovia: la ciudad, pp. 291, 441.

46 Según lo ha documentado Peribañez Otero, Territorio, sociedad y conflicto, pp. 345-346.

47 Diago Hernando, "La participación de la nobleza", p. 785.
} 
Si nos referimos al caso de Burgos, podría decirse que desde la década de 1440 se constatan problemas en relación con la ocupación de algunos oficios por parte de los parientes y criados de los regidores del concejo, así como en torno a los acostados que los miembros de la alta nobleza mantenían en la ciudad, fundamentalmente con los del mariscal Sancho de Estúñiga, alcaide de la fortaleza de Burgos.

La intromisión de criados, parientes y amigos de los alcaldes y regidores solía acarrear el abandono de las labores inherentes a los cargos en los que estas personas eran colocadas, ya que el puesto normalmente quedaba desatendido o se cubría con una persona inhábil para el cargo. En ocasiones, esta situación llegó a provocar problemas de índole judicial. Sirva de ejemplo el año de 1441, cuando parte de los alcaldes y el merino de la ciudad habían delegado la imposición de la justicia en manos de sus parientes, quienes impedían el buen ejercicio de la misma y no realizaban su labor ${ }^{48}$.

La ruptura del "buen gobierno" y la falta de "orden público" que estas acciones reflejaban ${ }^{49}$ dio lugar a amplios debates en el seno del concejo y motivó la emisión de una normativa destinada a prohibir este tipo de prácticas clientelares que, como se señalaba en 1433 por parte de los regidores, alcaldes y procuradores de la ciudad, impedían el buen ejercicio de la justicia ${ }^{50}$. De este modo, las Ordenanzas de Justicia de 1441 prohibían que tanto el merino como los alcaldes delegasen la imposición de la justicia en manos de sus parientes y allegados ${ }^{51}$. Asimismo, es en esta la línea en la que puede entenderse lo sucedido en 1433, cuando el concejo ordenaba al mariscal Sancho de Estúñiga que no tomase más acostados, pues estos estaban impidiendo el buen desarrollo de la justicia, en un momento en que la ciudad mantenía un enfrentamiento con el mariscal ${ }^{52}$.

También los monarcas emitieron prohibiciones destinadas a acabar con la toma de acostados y allegados por parte de los poderosos, como se observa para el año de $1463^{53}$. Sin embargo, no es hasta el 10 de septiembre de 1492 cuando los Reyes Católicos emitieron una pragmática por la que se prohibía a los "regidores, alcaldes, merinos, jurados, escribanos del concejo y mayordomos de las ciudades y villas de reino que viviesen con prelado o caballero, ni pública ni secretamente" ${ }^{\prime 54}$. En este caso, al igual que ocurría en varios de los núcleos del realengo a los que hemos hecho mención, tampoco fue acatada esta pragmática, cuya obligación de cumplimiento tuvo que ser recordada por la reina Juana I el 19 de junio de $1512^{55}$. Además, el 18 de febrero de 1514, la reina incorporaba un añadido a esta pragmática a petición de Burgos, pues el concejo requería conocer si esta prohibición se extendía también a los procuradores de las vecindades. De este modo, se especificó que ningún procurador

48 AMB, LLAA, 1441, f. 41rv.

49 Acerca de las nociones de bien común y servicio público en relación con las sociedades urbanas, véase: Jara Fuente, "Commo cunple a seruiçio", pp. 1-30; Idem, "Con mucha afección", pp. 52-82. Igualmente es esta noción la que articula el monográfico de María Álvarez Fernández sobre Oviedo (Álvarez Fernández, "Por ser bien común e público"). Asimismo, nótese cómo para el caso que nos ocupa la noción de bien común se une a la de justicia, cuestión que también se conjuga en: Monsalvo Antón, "En torno a la cultura contractual", pp. 159-209 y Bonachía Hernando, "La justicia en los municipios castellanos", pp. 145-182.

50 AMB, LLAA, 1433, f. 143rv.

51 AMB, LLAA, 1411, ff. 41r-44r.

52 AMB, LLAA, 1433, ff. 138v-139r.

53 AMB, LLAA, 1463, f. 108r.

54 AMB, HI, 3029. Inserta en la ordenanza del 19 de junio de 1512.

55 AMB, HI, 3029. 
de la ciudad de Burgos viviese "con prelado, caballero, regidor o persona poderosa, o recibiese de ellos acostamiento, quitación o ración" 56 . Dos meses más tarde, Juana I exigía al concejo burgalés que cumpliese lo ordenado en febrero, demostrándose así el incumplimiento sistemático de esta norma ${ }^{57}$.

No obstante, no en todos los casos el concejo fue igual de permisivo con estas intromisiones. Como veremos en el caso de Brizuela, el incumplimiento de este requisito fue uno de los argumentos esgrimidos de cara a frenar su acceso al regimiento. No había ocurrido lo mismo con otros criados de la nobleza, incluso con aquellos que también se encontraron vinculados a la casa de Velasco. En concreto, en 1506, Fernando de Bañuelos, mayordomo de Bernardino Fernández de Velasco, había accedido a un oficio de regidor sin que su vinculación con el condestable, que el concejo conoce y a la cual remite ${ }^{58}$, hubiese supuesto impedimento alguno ${ }^{59}$. A pesar de que en un primer momento el concejo alude al incumplimiento de Bañuelos del requisito de la vecindad y a que este "vive con" el condestable ${ }^{60}$, días después, una vez que Bañuelos ha probado su condición de vecino, es recibido sin que se objete nada nuevo en relación a su lazo con el condestable ${ }^{61}$. Tampoco se anotaba esta cuestión al recibir a Zumel ${ }^{62}$. Mientras que, por el contrario, Iván de Escobar en 1509 debía renunciar a su cargo como alcalde de Muñó -villa dependiente jurisdiccionalmente del concejo burgalés ${ }^{63}$ - debido a que, como nos hace saber él mismo, "vivía con" el condestable ${ }^{64}$. Sin duda, estas situaciones responden a los diferentes acuerdos y estrategias desarrolladas por el concejo de cara a permitir el acceso de la nobleza a los oficios urbanos.

Por otra parte, si nos referimos al procedimiento de designación de alcaldes, a finales del siglo XV y principios del XVI fueron dos los mecanismos por los que se accedió a este cargo. Por nombramiento directo del monarca, que emitía una carta de expectativa de oficio que posteriormente debía ser aceptada por el concejo, o bien a través de la renuncia del oficio que en favor del candidato realizaba el oficial anterior. Esta renuncia debía ser aceptada por el monarca, quien la autorizaba mediante la emisión de un privilegio, que finalmente debía ser presentado ante el concejo para que fuese obedecido. En caso de ser aceptado por parte del concejo, el candidato debía prestar el juramento requerido para ocupar la alcaldía, requisito último en su acceso al cargo ${ }^{65}$. La vía de la renuncia fue la opción más frecuente, de tal modo que

\footnotetext{
AMB, HI, 3031.
}

AMB, HI, 3265.

58 Así se observa claramente en 1507, cuando se anota que Bañuelos es mayordomo del condestable de Castilla (AMB, LLAA, 1507, f. 166rv).

59 AMB, LLAA, 1505, ff. 36v-39r. Como hemos comentado con anterioridad, Fernando de Bañuelos juró y tomó posesión de su cargo en 1506, un año después de que le hubiese sido concedido (AMB, LLAA, 1506, f. 199v).

60 AMB, LLAA, 1505, f. 17r.

${ }_{61}$ AMB, LLAA, 1505, ff. 36v-39r.

62 AMB, LLAA, 1515, ff. 121r-122v.

63 Acerca de los oficios municipales de las villas dependientes del concejo burgalés y de sus procedimientos de elección, véase Bonachía Hernando, El señorío de Burgos, pp. 112-148.

${ }^{64}$ AMB, LLAA, 1509, ff. 78r-80r. Iván de Escobar había accedido un año antes a dicha alcaldía (AMB, LLAA, 1508, f. 108r).

65 Como ha señalado Yolanda Guerrero Navarrete, se trata de un privilegio que no iba unido al oficio, aunque la mayoría de los alcaldes y regidores lo obtuvieron en el momento de su entrada al cargo o bien durante su ejercicio. Con anterioridad a 1461, normalmente en el momento de hacer efectiva la renuncia, se solicitaba nuevamente al rey la confirmación del privilegio que se había obtenido. Sin embargo, a partir de esa fecha se prescindió de este segundo requerimiento al monarca, de modo que el candidato solía presentar al concejo el privilegio, que ya estaba en su disposición, para su directa aprobación (Guerrero Navarrete, Organización y 
en Burgos los oficios se patrimonializaron, sucediéndose de manera vitalicia en los cargos padres e hijos por la vía de la renuncia. Además, con el objetivo de evitar la venalidad de los cargos, esta segunda vía requería dos condiciones para que pudiese ser efectiva: por un lado, para renunciar en favor de otro, la persona que renunciaba debía vivir, al menos, veinte días más después de que se hubiese realizado la renuncia y, por otro, esta debía hacerse de manera gratuita.

Nótese cómo en los dos procedimientos mencionados, la aprobación última de un candidato recaía en los oficiales del concejo con facultad de voz y voto, esto es, dieciséis regidores y seis alcaldes. En muchas ocasiones, como ha puesto de manifiesto Yolanda Guerrero Navarrete, las cartas regias de provisión de oficios emitidas por la Corona fueron contestadas por el concejo, que no aceptaba al candidato propuesto, normalmente porque incumplía alguno de los requisitos señalados o bien porque se consideraba que existía un candidato con mayores derechos o con mejor capacitación ${ }^{66}$. La negativa del concejo a aceptar a un candidato en determinado momento obligó al monarca a retirar su provisión en ciertas situaciones. Uno de estos ejemplos puede encontrarse entre los servidores de la casa de Velasco para 1478. Ese año, Gonzalo Pérez de Cartagena, oficial al servicio del II conde de Haro y futuro maestresala de Íñigo Fernández de Velasco, presentaba ante el concejo una provisión del monarca por la que se le otorgaba la alcaldía de Francisco Bocanegra ${ }^{67}$. Sin embargo, la presión ejercida por el concejo provocó que finalmente fuese elegido como alcalde Juan Bocanegra, hijo del alcalde anterior. En caso de existir desacuerdo en el seno del concejo por la aprobación de un candidato, alcaldes y regidores procedían a someter su aprobación a una votación que, como comprobaremos para el caso de Brizuela, determinaba la incorporación del solicitante al cargo.

Ambos mecanismos, la provisión directa del monarca y la vía de la renuncia, se documentan para los oficiales de la casa de Velasco. Dentro de la primera vía se inserta Fernando de Bañuelos, a quien Fernando el Católico en 1505 hacía merced del regimiento que había vacado en el lugar de Fernando de la Torre ${ }^{68}$. A partir de ese momento, esta regiduría se encontró vinculada a los condestables de Castilla, ya que en 1512 Bañuelos renunciaba a su cargo en favor de Antonio de Melgosa, tesorero de Bernardino Fernández de Velasco, que la ocupó hasta 1523, año en el que renunció en su hijo ${ }^{69}$. De igual manera, otros oficiales señoriales a los que nos hemos referido accedieron a sus cargos por la vía de la renuncia, como Juan de Zumel, que primero se incorporó a una alcaldía gracias a la renuncia que en 1505 hacía en su nombre Juan Osorio ${ }^{70}$, oficio al que posteriormente renunció en favor del maestresala del condestable, Gonzalo Pérez de Cartagena. Este último renunciaba, a su vez, en $\mathrm{Zu}$ mel su cargo de escribano mayor. Se da aquí una permutación de oficios por la vía de la renuncia entre dos oficiales de una misma casa señorial, Gonzalo de Cartagena renunciaba en Zumel y viceversa ${ }^{71}$. Igualmente, Brizuela habría obtenido la alcaldía a través de la renuncia de Francisco de Lerma, aunque esta solo fue la fachada legal de un proceso de acceso al concejo mucho más complejo, en el que se desarrollaron

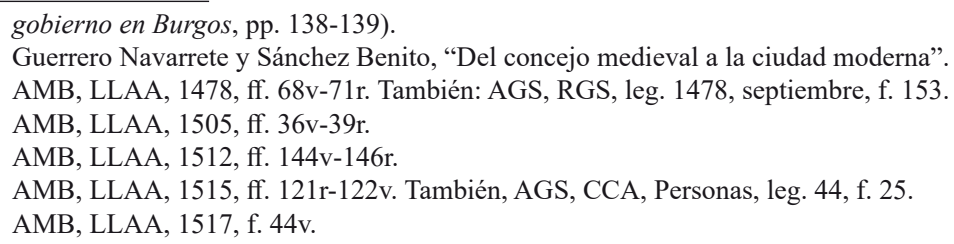


mecanismos y estrategias de diversa índole, no siempre legales, y a través de cauces no necesariamente institucionalizados, que a continuación pasamos a examinar.

\section{Estrategias desarrolladas en el acceso de Brizuela a la alcaldía. La disposición de un amplio capital relacional}

Atendiendo a la información que nos proporcionan las actas municipales burgalesas, concretamente a las dudas y quejas expresadas por parte del alcalde mayor García de la Mota y del regidor Pedro de Cartagena en el momento de la aprobación de la provisión de Brizuela a la alcaldía, es posible observar cómo Brizuela no cumplía con la mayoría de los requisitos que acabamos de señalar. El primero de los alegatos esgrimidos por García de la Mota en contra de la provisión de Brizuela es el de la vecindad:

García Ruíz de la Mota, alcalde mayor, dixo que obedesçia la dicha provisyon como carta de su reyna e príncipe, sus naturales señores a quien Dios dexe vivir e reynar por largos tiempos [...] en quanto al cumplimiento dixo que el dixo Francisco de Brizuela tiene çiertos ympedimientos por que no debe ser reçibido, lo uno, que no es vecino de esta çibdad e que la dicha çibdad tiene probisyon de que ningund que no fuese vecino se biba con señor no tenga ofiçio en esta dicha çibdad, e, que el dicho Brizuela no tiene fechas las deligençias que en la dicha probisyon se contiene e que fasta ser fechas estas e averiguardas no se debe recibir.

Como hemos apuntado con anterioridad, dos días antes de presentar la provisión regia, Francisco de Brizuela había solicitado al concejo la obtención de una carta de vecindad que, según se registra en el acta de la sesión correspondiente, le había sido concedida estando presente el dicho García de la Mota ${ }^{72}$. Es posible que este alcalde recurriese al alegato del incumplimiento del requisito de la vecindad porque esta aún no hubiese sido tramitada, o bien porque se tenía constancia de que Brizuela habría incumplido algunas de las obligaciones que iban anejas al avecindamiento.

Asimismo, en su argumento, García de la Mota señalaba el principal inconveniente por el que Brizuela no debía ser recibido; el hecho de que Brizuela "vive con señor", puesto que se encontraba, como su contador mayor, al servicio del condestable de Castilla. A pesar de que Francisco de Brizuela había tratado de negar este alegato, aduciendo que hacía tiempo que se había despedido de su servicio al condestable ${ }^{73}$. Sobre todo, García de la Mota insistía en que debía comprobarse si Brizuela cumplía las condiciones estipuladas en la provisión regia. A esta petición también se sumó el regidor Diego Osorio. En este sentido, la provisión regia señalaba cómo Brizuela solo podría tomar juramento del cargo si la renuncia se había hecho de acuerdo a la ley. Concretamente, se establecía que en dicha renuncia no podía haberse producido trueque, cambio o permutación alguna del oficio, es decir, que no se hubiese procedido a la venalidad del cargo que, como hemos apuntado, estaba prohibida. Además, para que la renuncia fuese legal, Francisco de Lerma debía haber vivido, al menos, veinte días más desde la fecha de la renuncia.

AMB, LLAA, 1516, f. 56r.

73 AMB, LLAA, 1516, ff. 18r-20v. 
Ambos regidores hacían hincapié en que se averiguase si la renuncia de Francisco de Lerma en Brizuela se había hecho atendiendo a estas cláusulas porque, de acuerdo con lo que el regidor Pedro de Cartagena expresaba en esa misma sesión del 16 de febrero, se tenía constancia de que Francisco de Lerma no había vivido el tiempo estipulado, sino que, por el contrario, habría permanecido muerto. Según el relato de Pedro de Cartagena, no había dudas acerca de la muerte de Francisco de Lerma, ya que durante este tiempo se había acudido a la casa del alcalde para entregarle una carta de emplazamiento, que fue recogida por sus hijos, quienes impidieron que se viese a su padre porque, con toda seguridad, ya estaba muerto. Esta circunstancia es la que hace suponer a Pedro de Cartagena que, contrariamente a la ley, Francisco de Lerma habría vendido su oficio a Brizuela. Además, este regidor reiteraba el hecho de que Brizuela vivía con el condestable y no era vecino de la ciudad, por lo que no se le debía recibir como alcalde mayor ${ }^{74}$. Se desprende de este testimonio que los hijos de Francisco de Lerma habrían estado ocultando la muerte de su padre para que pudiese producirse el traspaso del oficio, que finalmente debían haber vendido a Brizuela. De este modo, Francisco de Brizuela incumplía la normativa referente a la venalidad de los oficios municipales.

De lo apuntado hasta ahora es posible extraer una primera conclusión clara: el acceso de Francisco de Brizuela a la alcaldía de Burgos se habría realizado gracias a la venta fraudulenta del oficio que habrían efectuado los hijos de Francisco de Lerma a Brizuela. No es posible afirmar si detrás de esta venta se encontraba el condestable de Castilla, aunque, como enseguida se comprobará, lo que parece claro es que el acceso de Brizuela al cargo no pudo hacerse sin la intermediación del condestable de Castilla y del capital relacional del que este último disponía en la ciudad. Esta venta se habría disfrazado como una de las habituales renuncias que se producían en Burgos entre parientes o personas afines, consiguiendo así la autorización regia para que pudiera hacerse efectiva.

Sin embargo, el acceso de Brizuela a la alcaldía responde a una estrategia más compleja que no descansó solamente en la venta del oficio. Ya hemos apuntado cómo en Burgos, a pesar de que el candidato al oficio municipal hubiese adquirido una carta regia de merced que le facultaba para acceder al oficio, en la práctica, era el concejo quien finalmente decidía o no su aprobación. En caso de existir desacuerdo entre los oficiales municipales con motivo de la aceptación de un candidato, regidores y alcaldes sometían esta cuestión a votación.

Así ocurrió con la provisión de Francisco de Brizuela con la que varios regidores y alcaldes estuvieron en desacuerdo, debiendo procederse así a una votación. Por tanto, en último término, el 16 de febrero de 1516 Brizuela lograba ser aceptado como alcalde porque, frente a la oposición manifestada por varios oficiales municipales, contó con el apoyo de una parte del regimiento que votó a favor de que se aprobase lo contenido en la carta regia que ratificaba la renuncia y le facultaba para acceder al oficio. El examen pormenorizado de los alcaldes y regidores que dieron su voto a favor del acceso de Brizuela a la alcaldía de Burgos demuestra cómo casi todos ellos mantenían diversas relaciones de interdependencia con la casa de Velasco, cuestión que podría haber pasado inadvertida si no se recurre al análisis prosopográfico y relacional de cada uno de estos individuos. En este sentido, es posible encuadrarlos a todos en una misma red social dentro de ese marco concejil, que se articularía en

74 AMB, LLAA, 1516, ff. 59v-60r. 
torno a los condestables de Castilla y de la que Francisco de Brizuela formaría parte en 1516 como contador mayor de Íñigo Fernández de Velasco, VIII condestable de Castilla, II duque de Frías y IV conde de Haro. De este modo, su acceso a la alcaldía de Burgos no puede entenderse sin el análisis de las relaciones el condestable movilizó dentro de esta red social de cara a lograr el voto favorable para Brizuela.

De igual manera, es necesario señalar la propia posición que Francisco de Brizuela ocupó dentro de la red social de los condestables. Francisco era miembro de una de las familias más destacadas de la hidalguía local de Berlanga del Duero, villa de procedencia de María de Tovar, esposa de Iñigo Fernández de Velasco, en la que desde finales del siglo XV los Brizuela se encontraban bien asentados ${ }^{75}$. El padre de Francisco de Brizuela (1490-1551), Antonio Fernández de Brizuela, señor de la casa de Brizuela y alcaide de la fortaleza de Berlanga, había sido curador de María de Tovar. De esta manera, con el matrimonio entre María de Tovar y el II duque de Frías, los Brizuela quedaban vinculados también al servicio de la casa de Velasco. Concretamente, Francisco de Brizuela fue contador y mayordomo ${ }^{76}$ de Íñigo Fernández de Velasco y de su hijo Pedro Fernández de Velasco y Tovar, además de estar al frente de la alcaidía de Berlanga ${ }^{77}$. Este servicio a los condestables de Castilla también fue continuado por su hijo Alonso, paje de Íñigo Fernández de Velasco ${ }^{78}$.

Tras el matrimonio de ambos cónyuges, Brizuela había pasado a formar parte de la red del condestable y se habría trasladado a Burgos en 1512, cuando Íñigo Fernández de Velasco sucedió a su hermano al frente de la titularidad de la casa señorial, dejando de formar parte de los oficiales de la casa de la duquesa de Frías para actuar como contador del condestable. Es probable que el condestable de Castilla se hubiese percatado de las ventajas que Brizuela parecía mostrar en el acceso al concejo burgalés frente a otros oficiales señoriales, fundamentalmente porque Francisco de Brizuela se encontraba vinculado familiarmente con otro de los oficiales de la casa de Velasco presente en el regimiento, Fernando de Bañuelos, cuyo hijo, Gabriel de Bañuelos, había contraído matrimonio con la hija de Francisco de Brizuela, Juliana de Brizuela y Sarabia ${ }^{79}$. Asimismo, los Brizuela mantuvieron a lo largo del siglo XVI buenas relaciones con otros linajes burgaleses, como los Maluenda, los Melgosa ${ }^{80} \mathrm{o}$ los Soria, familia esta última con la que los Velasco mantenían también contactos ${ }^{81}$. Muy probablemente las conexiones familiares que este contador poseía en la ciudad motivaron al condestable a trasladar a Brizuela de su entorno originario de Berlanga a Burgos, en donde, a tenor de estas conexiones, podía tener mejores opciones que otros oficiales señoriales de ser aprobado en un cargo municipal.

$75 \quad$ Alós y Duque de Estrada, Los Brizuela condes de Fuenrubia, pp. II-IV.

76 Aparece desarrollando ambas tareas en los documentos conservados en la sección Frías, aunque parece que las menciones a su labor de mayordomo son anteriores a las de su posición como contador. Así, en 1514, es registrado como mayordomo del condestable, entregando ciertos maravedíes para la iglesia colegial de Santa María del Mercado en Berlanga (AHN, Nobleza, Frías, c. 1444, d. 18). Dos años más tarde, en los documentos de Burgos se le menciona ya como contador del II duque de Frías (AMB, LLAA, 1516, f. 57r). Bajo esta denominación aparece también en otros legajos de Frías (AHN, Nobleza, Frías, c. 93, d. 1-7, f. 38).

77 Alós y Duque de Estrada, Los Brizuela condes de Fuenrubia, pp. 3-7.

78 AHN, Nobleza, Frías, c. 93, d. 1-7, f. 38.

79 Alós y Duque de Estrada, Los Brizuela condes de Fuenrubia, p. 7.

80 Aunque Alós y Duque de Estrada no recogen el enlace entre en su obra, García Rámila menciona el matrimonio de un Melgosa con una mujer del linaje de Brizuela (García Rámila "Claros linajes burgaleses”, pp. 20-21).

81 Alós y Duque de Estrada, Los Brizuela condes de Fuenrubia, pp. 209-217. 


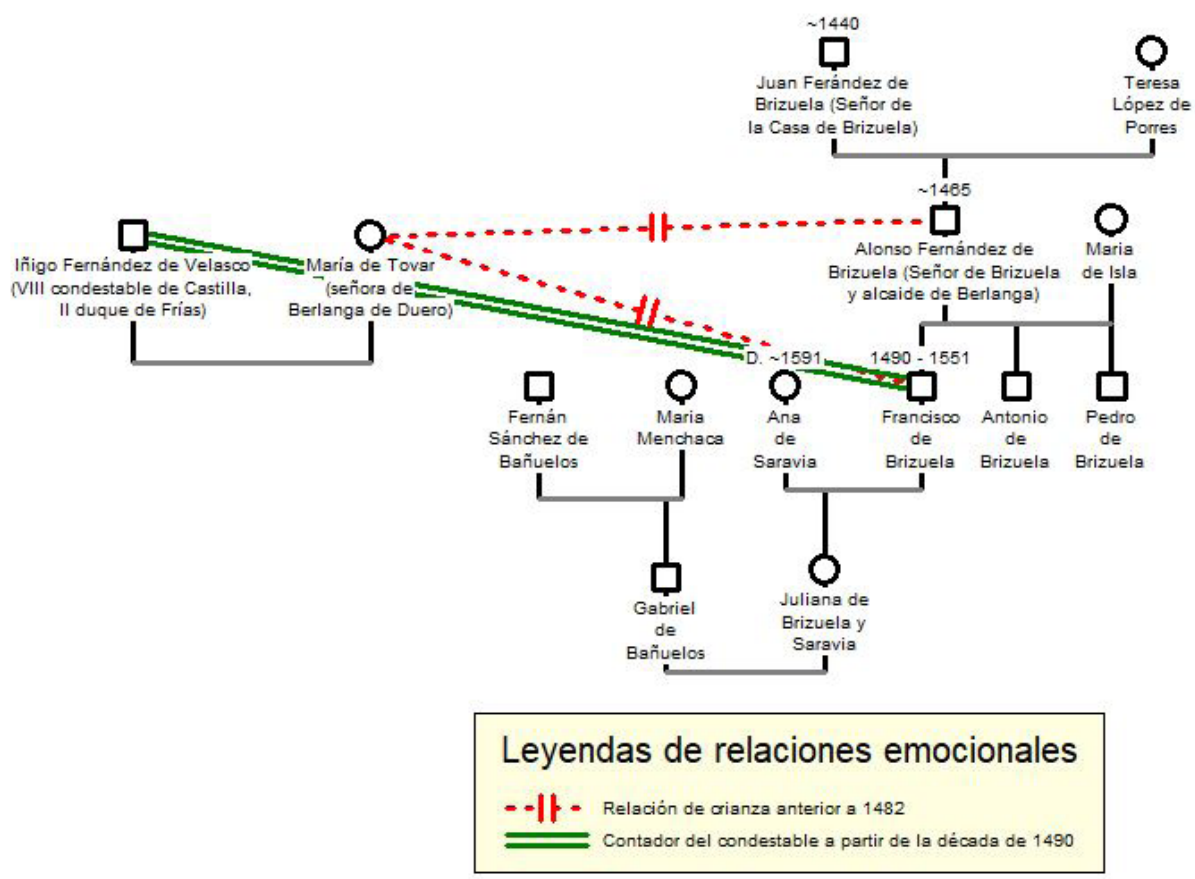

Figura 1. Familia Brizuela.

Por consiguiente, solo la participación de Brizuela en la red social que se fue articulando en Burgos desde finales del siglo XIV en torno a los sucesivos cabezas de la casa de Velasco habría garantizado su acceso a la alcaldía, cargo al que no habría podido acceder por sí mismo, aunque hubiese dispuesto del capital económico necesario para tramitar la venta con los hijos de Francisco de Lerma o de un cierto capital relacional. En este sentido, la obtención de un oficio municipal como una alcaldía y los beneficios a ella asociados deben ser leídos también en términos de capital social, en la medida en que la alcaldía habría sido un recurso que Brizuela solo habría logrado alcanzar a través de su participación en una red social determinada y a la movilización de recursos que tuvo lugar en ella ${ }^{82}$. Sobre todo, gracias a la disposición del capital relacional que el condestable habría movilizado en la ciudad para lograr el voto positivo para su contador.

Por su vinculación con el condestable, Francisco de Brizuela se habría visto beneficiado de las relaciones que Íñigo Fernández de Velasco mantenía con buena parte de los miembros del concejo, que, dentro de la red examinada, ocupaban un lugar privilegiado de cara a lograr el acceso de este oficial señorial a la alcaldía mayor de Burgos, ya que todos ellos eran oficiales municipales con derecho a voto. De acuerdo con lo registrado en las actas municipales el día 16 de febrero, en el momento de la presentación por parte de Brizuela de la carta regia de provisión del oficio de alcalde, representado en el Gráfico 1, se observan varias cuestiones que a continuación pasamos a explicar. 


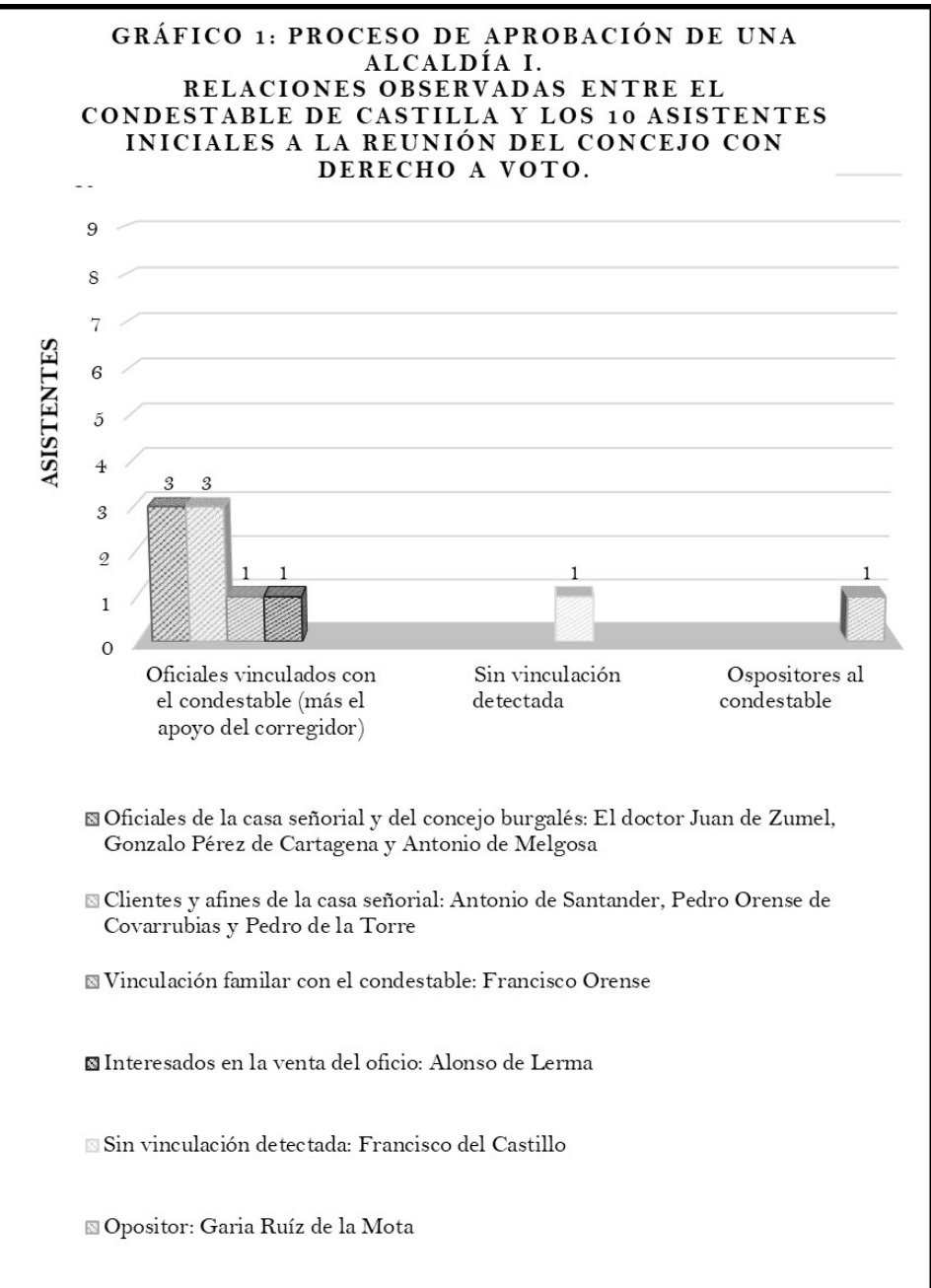

Gráfico 1. Proceso de aprobación de una alcaldía. I. Relaciones observadas entre el condestable de Castilla y los 10 asistentes iniciales a la reunión del concejo con derecho a voto.

De entrada, llama la atención que de los veintitrés oficiales que en ese momento tenían derecho a voto en la ciudad de Burgos (dieciséis regidores, seis alcaldes y el escribano mayor $)^{83}$, tan solo se encontraban presentes diez de ellos: los alcaldes, García de la Mota y Juan Zumel, y los regidores, Antonio de Melgosa, Antonio de Santander, Pedro Orense de Covarrubias, Pedro de la Torre, Alonso de Lerma, Fran-

83 En 1516, los seis alcaldes mayores de la ciudad eran los siguientes: Antonio Sarmiento, Francisco de Brizuela (al suceder a Francisco de Lerma), García Ruíz de la Mota, Juan de Zumel, Juan Manrique de Luna y Luis Barahona. Por su parte, las dieciséis regidurías estaban en manos de Antonio de Melgosa, Antonio de Santander, Antonio de Villegas, Martín de Salinas, Diego de Soria, Diego de Valdivieso, Diego Osorio, Fernando de Bernuy, Francisco del Castillo, Francisco Orense, Luis Sarmiento, Pedro de Cartagena, Pedro de la Torre, Pedro de Torquemada, Alonso de Lerma (al que sucede ese año Pedro Jiménez del Castillo) y Pedro Orense de Covarrubias. Mientras que el escribano mayor era Gonzalo Pérez de Cartagena y los dos procuradores mayores Nuño de Gomiel y Pedro Gómez de Valladolid. Finalmente, el oficio de merino recaía en Sancho de Rojas. 
cisco Orense y Francisco del Castillo. Junto con el escribano mayor, con derecho a voto por aquel entonces, y el corregidor regio, Francisco de Luján y su lugarteniente, Luis de Villaverde. La labor de estos últimos oficiales extraconcejiles se limitaba en estos casos a confirmar la decisión aceptada por la mayoría de los alcaldes y regidores. Por consiguiente, ni la mitad de los oficiales municipales con derecho a voto se encontraba presente. Asimismo, debe considerarse la ausencia del merino Sancho de Rojas, que solía ser frecuente, y, las no tan frecuentes ausencias de los dos procuradores mayores, Nuño de Gomiel y Pedro Gómez de Valladolid, representantes del común con facultad de voz en las sesiones de ayuntamiento, que comparecieron una vez iniciado el debate sobre la aceptación de Brizuela como alcalde.

Además, si se atiende a lo contenido en el Gráfico 1, que representa los asistentes documentados en el concejo en el momento de la presentación por parte de Brizuela del privilegio regio, se comprueba cómo la mayor parte de ellos mantenían una relación clientelar o de servicio con el condestable de Castilla. Tres de ellos formaban parte de la casa señorial: el alcalde mayor Juan de Zumel, como contador y consejero de Íñigo Fernández de Velasco; el escribano Gonzalo Pérez de Cartagena, como maestresala; y el regidor Antonio de Melgosa, como mayordomo. El primero habría logrado entrar en el concejo burgalés de la misma manera que ahora lo hacía Brizuela, mientras que los dos segundos formaban parte de dos familias con una honda raigambre en la ciudad y tradición de ocupar oficios municipales. Sus miembros, en cualquier caso, habían formado parte de la casa señorial de los Velasco desde que estos comenzaron a proyectar su presencia sobre la ciudad a finales del siglo XIV ${ }^{84}$. Asimismo, se registra al regidor Alonso de Lerma, familia de Francisco de Lerma y, por consiguiente, partícipe de la venta del oficio a Brizuela e interesado en que la renuncia se hiciese efectiva.

Junto con estos, otros de los oficiales presentes que se encontraron a favor de la aprobación de Brizuela habían mantenido diversas relaciones durante las décadas anteriores con Íñigo Fernández de Velasco y su hermano Bernardino. El análisis de estas relaciones, si bien no permite explicar por qué en este momento exacto estos oficiales apoyaron la alcaldía de Brizuela, ayuda a entender la posición favorable que adoptaron, siendo probable que el condestable hubiese aducido estas relaciones con el objetivo de influir en el sentido de su voto. Así sucedería con el regidor Francisco Orense, vinculado de alguna manera a los condestables a través de su sobrino Pedro de Velasco, hijo bastardo de su hermana Clara Orense y Bernardino Fernández de Velasco, II duque de Frías. Este bastardo había sido reconocido por el condestable y legitimado por Juana I y Fernando el Católico ${ }^{85}$, recibiendo a la muerte de su padre, en 1512, un amplio mayorazgo ${ }^{86}$. De este modo, es posible que, al igual que había ocurrido con su padre y anterior regidor Pedro Orense ${ }^{87}$, el vínculo parentelar condujese a Francisco Orense a mantener buenas relaciones con los condestables de Castilla, como prueba el hecho de que ese mismo año de 1516 fuese este regidor el encargado de mediar entre el concejo y el condestable la pacificación de la ciudad ${ }^{88}$.

\footnotetext{
84 Acerca de la relación clientelar y de servicio que los Cartagena mantuvieron con los condestables de Castilla a lo largo del siglo XV y principios del XV, véase Montero Málaga, "Lealtad compartida”, pp. 236-263.

85 AHN, Nobleza, Frías, c. 600, d. 16-22 y 25-26.

86 Franco Silva, Entre los reinados, pp. 116-117.

87 Son diversas las ocasiones en las que se puede ver a Pedro Orense como interlocutor entre los condestables de Castilla y el concejo. Baste como muestra AMB, LLAA, 1496, ff. 25r, 82r.

88 AMB, LLAA, 1516, ff. 33v-34r.
} 
Por su parte, el regidor Pedro Orense de Covarrubias desde su acceso en 1507 al concejo fue comisionado en numerosas ocasiones para tratar con los condestables diversos asuntos en nombre del concejo ${ }^{89}$. En otras, su participación en favor de los condestables fue más activa, como se observa en 1510, año en el que Pedro Orense de Covarrubias fue uno de los pocos oficiales concejiles que dieron su voto a favor de que el condestable de Castilla, Bernardino Fernández de Velasco, adquiriese del cabildo ciertos terrenos y vasallos colindantes con el alfoz urbano ${ }^{90}$. Asimismo, Pedro Orense de Covarrubias fue uno de los apoyos de Íñigo Fernández de Velasco en las Comunidades, llegando a prestar dinero y hombres para la batalla de Villalar ${ }^{91}$. Ejemplo similar es el que representa el regidor Pedro de Torquemada, que comparece en el ayuntamiento una vez presentada la petición de Brizuela, a quien es posible encontrar comisionado por parte del concejo ante los condestables ${ }^{22}$, habiendo quedado además registrado como uno de los apoyos del condestable en $1520^{93}$.

Finalmente, los casos de los regidores Pedro de la Torre y Antonio de Santander resultan algo más complejos. La relación de Antonio de Santander con la casa de Velasco varió enormemente entre finales del siglo XV y principios del siglo XVI. Aunque de manera general este regidor se opuso a las acciones que los miembros del linaje llevaron a cabo en la ciudad, siendo, por ejemplo, uno de los opositores a la entrada de Fernando de Bañuelos al regimiento en $1505^{94}$ o a la compra de los lugares del cabildo por parte del condestable que acabamos de mencionar para el año de 1510, en otras ocasiones se le puede documentar procediendo en favor de los condestables, como ocurre en este año de 1516. También actuando como mediador entre los titulares del linaje y el concejo ${ }^{95}$. Por otro lado, en lo que respecta a Pedro de la Torre, pudiera ser que este personaje guardase relación con su homónimo y maestresala del II conde de Haro, Pedro Fernández de Velasco, a quien se registra actuando en la ciudad el año de $1478^{96}$. Además de estos regidores, Francisco del Castillo también fue favorable a la aceptación de Brizuela, personaje para el que, sin embargo, no se documentada relación alguna con la casa de Velasco.

En suma, de acuerdo a lo que se refleja en el Gráfico 1, en el momento de presentación de la provisión de Brizuela, de los diez asistentes con derecho a voto, ocho mantendrían algún tipo de vinculación con el condestable: Juan de Zumel, Gonzalo Pérez de Cartagena, Antonio de Melgosa, Alonso de Lerma, Francisco Orense, Pedro de Torquemada, Pedro Orense de Covarrubias, Antonio de Santander y Pedro de la Torre; uno no mantendría relación aparente, aunque finalmente votaría a favor, Francisco del Castillo; mientras que el décimo, el regidor García de la Mota, se encontraba en contra de la designación de Brizuela.

Sobre este opositor presente desde el primer momento, es necesario remitir brevemente a lo que ocurrió ese año en la ciudad. A comienzos de 1516, en el contexto de inestabilidad que viven muchas de las ciudades castellanas a la muerte de Fernando el Católico, Íñigo Fernández de Velasco, VIII condestable de Castilla y II duque

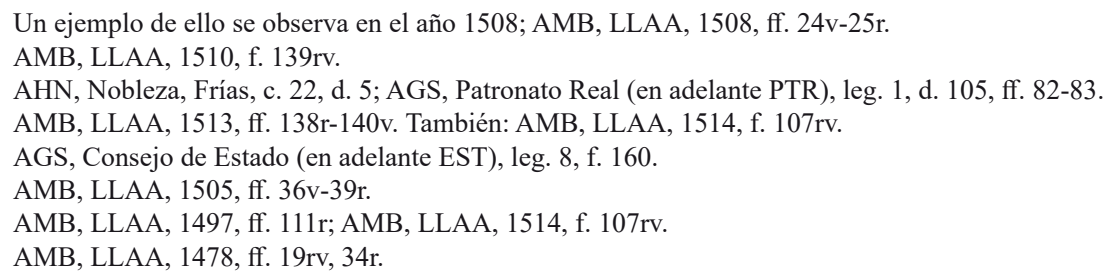


de Frías, había sacado sus armas a la calle y había tratado de controlar militarmente la ciudad de Burgos ${ }^{97}$. Sin entrar en el desarrollo de estos episodios ni en las causas concretas que motivaron esta reacción del condestable, conviene señalar cómo Íñigo Fernández de Velasco contó con el apoyo de parte de los oficiales concejiles, que se encontraron adscritos a su parcialidad. En particular, con los regidores Diego de Valdivieso, Martín de Salinas, Diego de Soria, Juan de Zumel, Gonzalo Pérez de Cartagena y su hijo Juan Pérez de Cartagena y Antonio de Melgosa. Además de con la ayuda del deán de la catedral Pedro Suárez, del abad de Castro y de Escalada, del comendador del Hospital del Rey, del obispo de Palencia, Juan Fernández de Velasco, del conde de Miranda del Castañar y de los mercaderes Francisco de Mazuelo y Gregorio de Polanco. Y con el beneplácito del corregidor Francisco de Luján, que le hacía entrega de la fortaleza de la villa de Lara, dependiente del concejo burgalés. Como premio por sus servicios prestados en estos episodios, así como por la buena relación que mantenía con su familia, el condestable situó al frente de la misma a Juan Pérez de Cartagena, hijo del escribano mayor Gonzalo Pérez de Cartagena ${ }^{98}$.

En este contexto, fueron pocos los oficiales municipales que se opusieron. Fundamentalmente se trató de Diego Osorio, García de la Mota, Antonio Sarmiento, Luis Sarmiento y de Pedro de Cartagena, que por aquel entonces se encontraba enfrentado por cuestiones familiares al condestable, a pesar de que su familia había sido -y erala gran valedora de los Velasco en la ciudad ${ }^{99}$. En este contexto, cabe señalar cómo parece que algunos de estos personajes llamaron en su defensa al II duque de Nájera, Antonio Manrique, con el que se encontraban relacionados, especialmente Antonio Sarmiento y Luis Sarmiento ${ }^{100}$. Por aquel entonces, Antonio Manrique era enemigo del condestable y contrario a la llegada de Carlos V a Castilla, postura contrapuesta a la defendida por İ̃nigo Fernández de Velasco ${ }^{101}$.

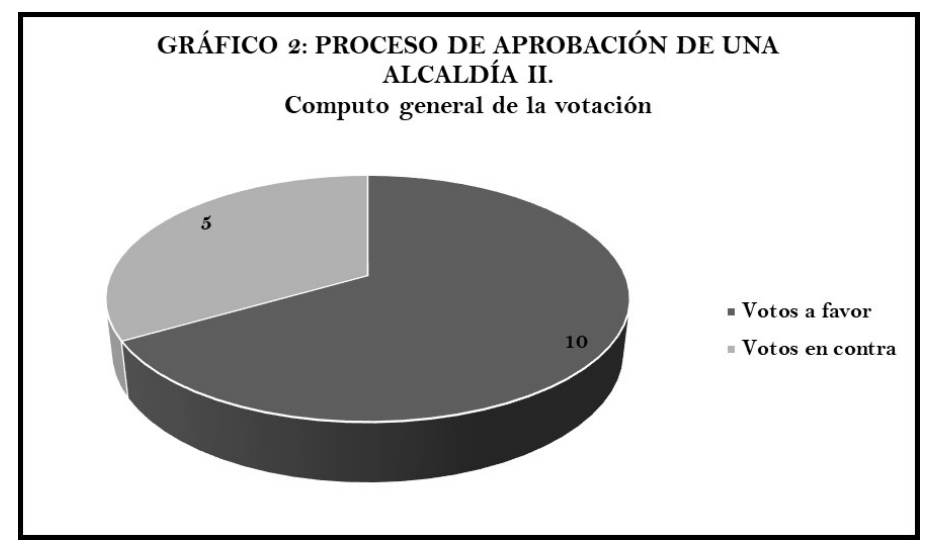

Gráfico 2. Proceso de aprobación de una alcaldía. II. Cómputo general de la votación.

\footnotetext{
97 Estos episodios han sido examinados en Montero Málaga, “Al grito de ¡Velasco, Velasco!".

98 AGS, Estado, leg. 1-2, f. 423; AGS, Estado, leg. 3, f. 23.

99 Montero Málaga, "Lealtad compartida", pp. 236-263.

100 Padre e hijo debieron de apoyar en 1507 al I duque de Nájera, Pedro Manrique, en el enfrentamiento que este mantuvo en Burgos con Bernardino Fernández de Velasco por la tenencia del castillo, que el condestable reclamaba para Fernando el Católico, mientras que el duque de Nájera era partidario del bando flamenco (Biblioteca Nacional Española (en adelante BNE), Manuscritos, Mss. 2018, f. 61r; BNE, Manuscritos, Mss. 3228, ff. 58v-59r). Sobre este enfrentamiento: AMB, LLAA, 1507, ff. 4r, 17r.

101 López Pita, "Nobleza y monarquía”, pp. 171-172.
} 


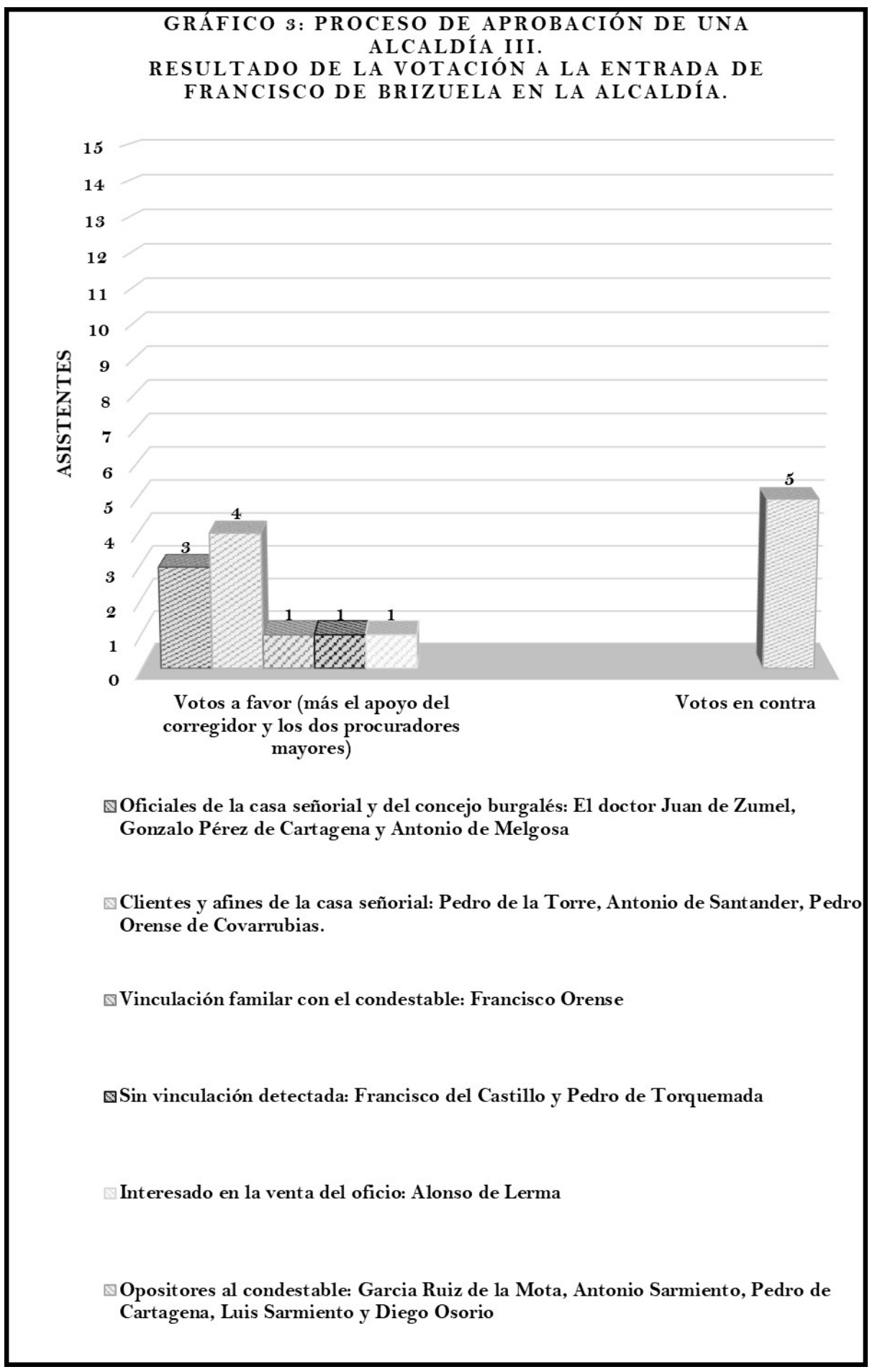

Gráfico 3. Proceso de aprobación de una alcaldía. III. Resultado de la votación a la entrada de Francisco de Brizuela en la alcaldía. 
Son estos últimos cinco personajes los que votaron en contra de la llegada de Brizuela a la alcaldía, proporcionándonos toda una lista de argumentos que nos han permitido conocer cómo Brizuela incumplía la mayor parte de requisitos. Salvo García de Mota, todo ellos acudieron a votar ya empezada la sesión del ayuntamiento y tras la presentación de Brizuela de la carta regia, según se contiene en el Gráfico 3. Probablemente avisados por García de la Mota, acudieron a votar en contra de los intereses del que por esos meses era su enemigo: el condestable de Castilla. Aun así, se comprueba cómo el nombramiento de Brizuela tuvo una mayoría de votos favorables. Los de los ocho oficiales presentes desde el primer momento que mantenían diversos tipos de relaciones con el condestable, a los que se suma el del regidor Francisco del Castillo, y el voto de Pedro de Torquemada, quien se incorpora en un segundo momento a la sesión. Asimismo, parece que la provisión de Brizuela contó con el apoyo de los dos procuradores mayores y del corregidor, que en último lugar confirmó lo aceptado por la mayoría de regidores y alcaldes. De este modo, como puede comprobarse en los Gráficos 2 y 3 , con un total de 10 votos a favor y 5 en contra, Brizuela era aceptado como alcalde y tomaba posesión de su cargo el 16 de febrero de 1516.

Por último, llama la atención el hecho de que de los veintiséis oficiales con derecho a voto en la ciudad, ese día hubiesen acudido casi todos aquellos con los que los Velasco mantenían relación, hecho que muy probablemente indica una planificación detallada por parte del condestable, que incluía la obtención de la carta de vecindad, posiblemente la elección del día en el que se iba a presentar la carta regia de provisión del oficio, la previsión de la asistencia al concejo de todos aquellos con los que mantenía una relación favorable, etcétera. No obstante, es necesario señalar algunas ausencias destacadas como la de los regidores Diego de Soria y Martín de Salinas, que ese año de 1516 formaban parte de la parcialidad velasquista. Aunque, en cualquier caso, el condestable parecía haberse asegurado una mayoría suficiente.

\section{A modo de conclusión}

De entrada, más allá de los datos que sobre este hecho se pueden obtener acerca del sistema de elección de oficios municipales en Burgos a comienzos del siglo XVI, lo que nos permite es comprobar cuáles fueron los mecanismos y estrategias puestas en marcha por los grandes señores para situar a sus clientes y afines en el concejo municipal. Una simple lectura de los escasos datos consignados en la documentación municipal acerca del acceso de Brizuela a la alcaldía podría conceder gran valor a la movilización del capital económico de la aristocracia en el acceso de los suyos a los oficios urbanos, si se atiende en exclusiva a la venta del oficio. Sin embargo, un examen más detallado del proceso de elección, y de los agentes presentes en el momento de la aceptación de la carta regia, permite afirmar cómo el acceso de Brizuela a la alcaldía solo fue posible gracias al capital relacional movilizado en 1516 por el condestable de Castilla. Al respecto, conviene destacar que, aunque aquí hemos analizado el capital relacional del que los Velasco disponían en 1516 en el concejo burgalés, sacando una foto fija de la red social, lo cierto es que entre 1470 y 1520 dicha red apenas sufrió variaciones, a pesar de que sí cambiaron los titulares del linaje. Asimismo, es necesario señalar cómo el ejemplo de Francisco de Brizuela no fue exclusivo, sino que otros oficiales concejiles adscritos a esta casa señorial tam- 
bién necesitaron del capital relacional que su inserción en la red del condestable les proporcionaba para poder acceder a sus oficios. En este sentido, otro de los ejemplos más significativos lo representa el de Gonzalo de Cartagena, al que ya nos hemos venido refiriendo. A pesar de que en 1492 este oficial había accedido a la escribanía mayor de Burgos a través de una merced regia a la muerte del escribano anterior Fernando de Covarrrubias, lo cierto es que desde 1478 Gonzalo de Cartagena había ambicionado un puesto de alcalde en la ciudad, que ese año de 1478 le era concedido mediante una carta regia de expectativa de oficio, pero al que, sin embargo, no pudo acceder, como consecuencia de la fuerte oposición presentada por varios de los regidores y alcaldes ${ }^{102}$. Solo en 1517 Gonzalo de Cartagena lograba alcanzar su objetivo, gracias a la renuncia que hacía de su alcaldía Juan de Zumel, oficial como él, al servicio de la casa de Velasco, lo que sin duda habría permitido que se realizara esta renuncia entre ambos ${ }^{103}$. Por otro lado, es necesario mencionar que, si bien la alcaldía puede ser entendida en términos de capital social para Brizuela, también lo fue para el propio condestable, quien se benefició de la inserción de uno de sus oficiales señoriales en el órgano de la gobernación municipal.

En definitiva, destaca el interés que adquiere el examen del análisis relacional y de sus correlativas nociones de capital social y capital relacional en las relaciones ciudad-nobleza. Nociones inseparables de los conceptos de posición y relación. En último término, el acceso de Brizuela a una alcaldía nos permite reflexionar acerca del significado y operatividad que puede tener un oficio municipal en función de quién lo ocupe, en este caso, un oficial señorial vinculado a la casa de Velasco. Así, se hace necesario examinar no solo el oficio como tal o sus funciones, sino la posición que ocuparon dentro del sistema urbano los diferentes alcaldes, como Brizuela, y la capacidad de relación de los mismos, cuestión sobre la que han llamado la atención repetidas veces José María Monsalvo, para el caso de Alba de Tormes, o José Antonio Jara, para el caso conquense ${ }^{104}$.

Por último, no queremos dejar aquí de señalar el éxito que tuvo la movilización del capital relacional por parte del condestable de cara a lograr el acceso de Brizuela a la alcaldía. Sin embargo, hemos de mencionar que se trató de un éxito relativo, pues, en el largo plazo, las presiones ejercidas por varios miembros del regimiento contrarios a su nombramiento como alcalde, junto con las irregularidades manifiestas en el acceso al cargo provocaron que, catorce meses después de su entrada en el regimiento, Carlos I le desposeyese de su oficio, nombrando en su lugar a Alonso Díez de Cuevas ${ }^{105}$. Por consiguiente, el capital relacional del condestable solo fue capaz de funcionar a un nivel local, pero no en otros ámbitos como la propia corte, en donde sin duda también debieron competir los intereses de otros nobles, como los del propio duque de Nájera, si bien es cierto que, tras las Comunidades, el condestable solicitó al monarca la provisión de una regiduría para Brizuela en Salamanca ${ }^{106}$.

102 AMB, LLAA, 1478, ff. 68v-71r.

103 AMB, LLAA, 1517, f. 88r.

104 Así lo ha expresado José María Monsalvo Antón, señalando cómo "un cargo no siempre es un cargo", puesto que "un mismo oficio municipal funcionaba de forma diferente dependiendo de quién lo ocupara", Monsalvo Antón, "Gobierno municipal”, p. 425. Además, véase: Monsalvo Antón, "El reclutamiento del personal", pp. 173-195; Idem, El sistema politico concejil; Jara Fuente, Concejo, poder y élites.

105 AMB, LLAA, 1517, f. 87r. Insertas provisiones regias.

106 Solicita el regimiento que vacó por Diego de Guzmán. AGS, Estado, leg. 2-2, f. 300. También: AGS, PTR, leg. 1, d. 105 , f. 126 . 


\section{Bibliografía}

Alegre Carvajal, Esther, "Prestigio, ciudad y territorio. Berlanga del Duero y los Duques de Frías", Tiempos modernos, 18 (2009/1), disponible en htt://www.tiemposmodernos.org/tm3/index.php/tm/article/viewFile/147/199.

Alós, Fernando y Duque de Estrada, Dolores, Los Brizuela condes de Fuenrubia y Familias Enlazadas, Madrid, 2009.

Álvarez Álvarez, César, "Linajes nobiliarios y oligarquías urbanas en León", en La nobleza peninsular en la Edad Media. VI Congreso de estudios medievales, León, 1999, pp. 35-65.

- "Oficiales y funcionarios concejiles de la Corona de Castilla durante la Baja Edad Media: (un largo proceso de intervención regia y oligarquización)", en Las sociedades urbanas en la España medieval. XXIX Semana de Estudios Medievales. Estella, 15 a 19 de julio de 2002, Pamplona, 2003, pp. 489-540.

Álvarez Fernández, María, "La ciudad de Oviedo durante el reinado de los Reyes Católicos" en Luis Ribot, Julio Valdeón y Elena Maza (coords.) Isabel la Católica y su época. Actas del Congreso Internacional, Valladolid, 2004, vol. I, pp. 545-567.

- Por ser bien común e público. Experiencias políticas y praxis urbana en el Oviedo de 1500, Oviedo, 2014.

- "Por ser hombre de más honra: comportamientos urbanos y plataformas del poder en una ciudad de transición”, en María Ángeles Faya Díaz (coord.), Las ciudades españolas en la Edad Moderna: oligarquias urbanas y gobierno municipal, Oviedo, 2014.

Asenjo González, María, Segovia: la ciudad y su tierra a fines del Medievo, Segovia, 1986.

Bonachía Hernando, Juan Antonio, El concejo de Burgos en la Baja Edad Media (1935-1426), Valladolid, 1978.

- El señorío de Burgos durante la Baja Edad Media (1255-1508), Valladolid, 1988.

— "La justicia en los municipios castellanos bajomedievales", Edad Media. Revista de Historia, 1 (1998), pp. 145-182.

Bourdieu, Pierre, "Le capital social", Actes de la Recherche en Sciences Sociales, 31 (1980), pp. 2-3.

- "The Forms of Capital", en John Richardson (ed.), Handbook of Theory and Research for the Sociology of Education, Nueva York, 1986, pp. 241-258.

Cabrera Muñoz, Emilio, "Usurpación de tierras y abusos señoriales en la sierra cordobesa durante los siglos XIV-XV", en Actas del I Congreso de Historia de Andalucía medieval, Córdoba, diciembre de 1976, Córdoba, 1978, vol. II, pp. 33-112.

Cabrera Sánchez, Margarita, Nobleza, oligarquía y poder en Córdoba al final del siglo XV , Córdoba, 1998.

Collantes de Terán, Antonio, Sevilla en la Baja Edad Media: la ciudad y sus hombres, Sevilla, 1977.

Cortes de los antiguos reinos de León y Castilla, Madrid, 1866-1903.

Dacosta Martínez, Arsenio, Los Linajes de Bizkaia en la Edad Media: poder, parentesco y conflicto, Bilbao, 2003.

Diago Hernando, Máximo, "El poder de la nobleza en los ámbitos regionales de la Corona de Castilla a fines del Medievo: las estrategias políticas de los grandes linajes en la Rioja hasta la revuelta comunera”, Hispania, 223 (2006), pp. 501-546. 
- "La participación de la nobleza en el gobierno de las ciudades europeas bajomedievales. Análisis comparativo", Anuario de Estudios Medievales, 37/2 (2007), pp. 781-822.

- "La proyección de las casas de la alta nobleza en las sociedades políticas regionales: el caso soriano a fines de la Edad Media", Anuario de Estudios Medievales, 39/2 (2009), pp. 843-876.

- "Intervencionismo de la alta nobleza en la vida política de las ciudades castellanas a fines de la Edad Media: los mariscales de Castilla en Soria", Edad Media: Revista de Historia, 15 (2014), pp. 245-271.

Díaz de Durana, José Ramón, La lucha de bandos en el País Vasco, de los parientes mayores a la hidalguía universal: Guipúzcoa, de los bandos a la provincia (siglos XIV a XVI), Bilbao, 1998.

Díaz de Durana, José Ramón y Fernández de Larrea Rojas, Jon Andoni, "Las relaciones contractuales de la nobleza y las élites urbanas en el País Vasco a final de la Edad Media (c.1300-1500)", en François Foronda y Ana Isabel Carrasco Manchado (dirs.), El contrato político en la Corona de Castilla. Cultura y sociedad políticas entre los siglos X al XVI, Madrid, 2008, pp. 238-321.

- "Las villas cantábricas bajo el yugo de la nobleza. Consecuencias sobre los gobiernos urbanos durante la época Trastámara”, en José María Monsalvo Antón (ed.), Sociedades urbanas y culturas políticas en la Baja Edad Media castellana, Salamanca, 2013, pp. 49-71.

Edvinsson, Leif y Malone, Michael, Intellectual Capital: Realizing your Company's True Value by Finding its Hidden Brain Power, Nueva York, 1997.

Franco Silva, Alfonso, "Pedraza de la Sierra. El proceso de formación de unas ordenanzas de villa y tierra en los siglos XIV y XV", Historia, Instituciones y Documentos, 18 (1991), pp. 97-142.

- Entre los reinados de Enrique IV y Carlos V. Los condestables del linaje Velasco. (1461-1559), Jaén, 2006.

- "El gobierno y la administración de un señorío. El modelo de los Velasco (13681470)", en José María Mínguez Fernández y Gregorio del Ser Quijano (coords.), La Península Ibérica en la Edad Media: treinta años después. Estudios dedicados a José Luis Martín, Salamanca, 2006, pp. 137-142.

- "Notas sobre la capilla del condestable de la catedral de Burgos", en Castilla y el mundo feudal. Homenaje al profesor Julio Valdeón, Valladolid, 2009, vol. I, pp. 441-451.

- "El reparto de los bienes no vinculados de Pedro Fernández de Velasco (13841399). Una historia de ambición y codicia”, Cuadernos de Historia de España, LXXXIII (2009), pp. 51-80.

García Fernández, Ernesto, Gobernar la ciudad en la Edad Media: Oligarquías y élites urbanas en el País Vasco, Vitoria, 2004.

- "Teorías y praxis política en el País Vasco a fines de la Edad Media: los gobiernos urbanos y los vecinos de la Tierra", en José María Monsalvo Antón (ed.), Sociedades urbanas y culturas politicas en la Baja Edad Media castellana, Salamanca, 2013, pp. 71-123.

García Marín, José María, El oficio público en Castilla durante la Baja Edad Media, Madrid, 1987.

García Rámila, Ismael, "Claros linajes burgaleses: los Melgosa [1]”, Boletín Institución Fernán González, 102 (1948), pp. 19-33. 
González Crespo, Esther, Elevación de un linaje nobiliario castellano en la Baja Edad Media: Los Velasco, tesis doctoral inédita defendida en la Universidad Complutense de Madrid, Facultad de Geografía e Historia, Departamento de Historia Medieval, 1980, 2 vols.

Guerrero Navarrete, Yolanda, "Fórmulas de transmisión del poder en el sistema oligárquico burgalés del siglo XV", en Actas del I Congreso Nacional de historia de Burgos, Burgos, 1984, pp.173-183.

- Organización y gobierno en Burgos durante el reinado de Enrique IV de Castilla. 1453-1476, Madrid, 1986.

- y José María Sánchez Benito, “Del concejo medieval a la ciudad moderna. El papel de las cartas expectativa de oficios ciudadanos en la transformación de los municipios castellanos bajomedievales: Burgos y Cuenca", en Manuel González Jiménez (ed.), La Península Ibérica en la era de los descubrimientos (1391-1492). III Jornadas Hispano-Portuguesas de Historia Medieval 25-30 de noviembre, Sevilla, 1997, vol. II, pp. 1097-1109.

Hergueta, Domingo, Noticias históricas del doctor Zumel, Burgos, 1923.

Imízcoz Beunza, José María, "El capital relacional. Relaciones privilegiadas y redes de influencia en el Estado español del siglo XVIII", en José María Imízcoz Beunza y Oihane Oliveri Korta (eds.), Economía doméstica y redes sociales en el Antiguo Régimen, Madrid, 2010, pp. 227-282.

Jara Fuente, José Antonio, "La nobilización de un concejo en el siglo XV: Cuenca y los Hurtado de Mendoza”, en Manuel González Jiménez (ed.), La Península Ibérica en la era de los descubrimientos (1391-1492): Actas de las III Jornadas Hispano-Portuguesas de Historia Medieval. Sevilla, 25-30 de noviembre de 1991, Sevilla, 1997, vol. II, pp. 1025-1034.

- Concejo, poder y élites. La clase dominante en Cuenca en el siglo XV, Madrid, 2000.

- "Commo cunple a seruiçio de su rey e sennor natural e al procomún de la su tierra $e$ de los vecinos e moradores de ella. La noción de 'servicio público' como seña de identidad política comunitaria en la Castilla urbana del siglo XV" en Isabel Alfonso Antón (coord.), "Cultura, lenguaje y prácticas políticas en las sociedades medievales”, e-Spania, número monográfico, 4 (2007), pp. 1-30.

- "Haciendo frente a las depredaciones señoriales. La defensa de las jurisdicciones municipales en la Castilla de la Baja Edad Media", Imago Temporis. Medium Aevum, 1 (2007), pp. 280-299.

- "Con mucha afección e buena voluntad por servir al bien público: La noción de 'bien común' en perspectiva urbana. Cuenca en el siglo XV', Studia Histórica. Historia Medieval, 28 (2010), pp. 52-82.

- "Didáctica de las relaciones políticas ciudad-nobleza en la Cuenca del siglo XV. Cerçada de muchos contrarios", Edad Media: Revista de Historia, 14 (2013), pp. 105-127.

- "Disciplinando las relaciones políticas: ciudad y nobleza en el siglo XV", en José María Monsalvo Antón (ed.), Sociedades urbanas y culturas políticas en la Baja Edad Media castellana, Salamanca, 2013, pp. 165-231.

Jones Mathers, Constance, "Cómo llegar a ser regidor. Primera parte", Boletín de la Institución Fernán González, 195 (1980), pp. 327-353.

- "Cómo llegar a ser regidor. Segunda parte", Boletín de la Institución Fernán González, 196 (1981), pp. 27-52. 
Jular Pérez-Alfaro, Cristina, "Dominios señoriales y relaciones clientelares en Castilla: Velasco, Porres y Cárcamo (siglos XIII-XIV)”, Hispania, 192 (1996), pp. 137-171.

- "Nobleza y clientelas, el ejemplo de los Velasco", en Carlos Estepa Díez y Cristina Jular Pérez-Alfaro (dirs.), Los señorios de Behetría, Madrid, 2001, pp. 145-186.

- "Porque tengo obligación: genealogía, escritura e identidad nobiliarias. Los Velasco", en Mónica Castillo Lluch y Marta López Izquierdo (eds.), Modelos latinos en la Castilla medieval, Fráncfort del Meno, 2010, pp. 307-329.

- "Los solares de don Haly. Liderazgo y registro escrito de la Casa de Velasco en el siglo XIV", Stvdia Zamorensia, Segunda Etapa, XII (2013), pp. 57-87.

- "La importancia de ser antiguo. Los Velasco y su construcción genealógica", en Arsenio Dacosta Martínez, José Ramón Prieto Lasa y José Ramón Díaz de Durana, (eds.), La conciencia de los antepasados, Madrid, 2014, pp. 201-237.

Ladero Quesada, Miguel Ángel, Andalucía en el siglo XV. Estudios de Historia Política, Madrid, 1973.

Layna, Francisco, Historia de Guadalajara y sus Mendozas en los siglos XV-XVI, Madrid, 1941-1946.

López Pita, Paulina, "Nobleza y monarquía en el tránsito a la Edad Moderna. Títulos y grandes en el movimiento comunero", en María Concepción Quintanilla Raso (dir.), Títulos, Grandes del Reino y Grandeza en la Sociedad Política. Fundamentos en la Castilla medieval, Madrid, 2006, pp. 163-175.

Martín Romera, María Ángeles, Las redes sociales de la oligarquía de la villa de Valladolid (1450-1520), tesis doctoral inédita leída en la U n i v e r s i d a d Complutense de Madrid, Facultad de Geografía e Historia, Departamento de Historia Medieval, 2012-07-13.

Monsalvo Antón, José María, "El reclutamiento del personal político concejil. La designación de corregidores, alcaldes y alguaciles en un concejo del siglo XV", Studia Historica. Historia Medieval, 5 (1987), pp. 173-195.

- El sistema político concejil. El ejemplo del señorío medieval de Alba de Tormes y su concejo de villa y tierra, Salamanca, 1988.

- "La sociedad política en los concejos castellanos de la Meseta durante la época del Regimiento medieval. La distribución social del poder", en Concejos y ciudades en la Edad Media hispánica. II Congreso de Estudios Medievales de la Fundación Sánchez Albornoz, León, 1989, Ávila-León, 1990, pp. 359-413.

- "Gobierno municipal, poderes urbanos y toma de decisiones en los concejos castellanos bajomedievales (consideraciones a partir de concejos salmantinos y abulenses)", en Las sociedades urbanas en la España medieval. XXIX Semana de Estudios Medievales. Estella, 15 a 19 de julio de 2002, Pamplona, 2003, pp. 409-488.

- "En torno a la cultura contractual de las élites urbanas: pactos y compromisos políticos (linajes, bandos de Salamanca, Ciudad Rodrigo y Alba de Tormes)", en François Foronda y Ana Isabel Carrasco Manchado (dirs.), El contrato político en la Corona de Castilla. Cultura y sociedad políticas entre los siglos X al XVI, Madrid, 2008, pp. 159-209.

- "Usurpaciones de comunales. Conflicto social y disputa legal en Ávila y su tierra durante la Baja Edad Media", Historia Agraria, 24 (2010), pp. 81-121.

- "Torres, tierras, linajes. Mentalidad social de los caballeros urbanos y de la élite dirigente en la Salamanca medieval (siglos XIII-XV)", en José María Monsalvo 
Antón, (ed.), Sociedades urbanas y culturas políticas en la Baja Edad Media castellana, Salamanca, 2013, pp. 165-231.

- (ed.), Sociedades urbanas y culturas políticas en la Baja Edad Media castellana, Salamanca: Universidad de Salamanca, 2013.

Montero Málaga, Alicia Inés, "Lealtad compartida. ¿Servir al rey, a la nobleza o a la ciudad?: Burgos y el linaje de los Cartagena a fines del siglo XV", Roda da Fortuna, 1/1 (2015), pp. 236-263, disponible en https://www.revistarodadafortuna. com/2015-1-1.

- "Al grito de ¡Velasco, Velasco!: Algunas consideraciones en torno al ejercicio del poder urbano en 1516", en Víctor Muñoz Gómez y Eduardo Aznar Vallejo (coords.), Hacer historia desde el medievalismo. Tendencias, Reflexiones, Debates, La Laguna, 2016, pp. 89-119.

Moreno Ollero, Antonio, Los dominios señoriales de la Casa de Velasco en la Baja Edad Media, Cádiz, 2014.

Muñoz Gómez, Víctor, "Conflictos de límites y aprovechamientos comunales: rivalidad concejil e intereses señoriales en la Extremadura castellana bajomedieval (El caso de Cuéllar y Peñafiel bajo el señorío del infante Fernando de Antequera", en Adolfo Carrasco Martínez (ed.), Conflictos y sociedades en la Historia de Castilla y León, Valladolid, 2010, pp. 209-223.

Ortega Cervigón, José Ignacio, "El intrusismo nobiliario en los concejos castellanos: el oficio de guarda mayor de Cuenca durante el siglo XV", en Juan Francisco Jiménez Alcázar, Jorge Ortuño Molina, y Jorge Eiroa Rodríguez (eds.), Actas I Simposio de Jóvenes Medievalistas Lorca 2002, Murcia, 2003, pp. 147-178.

- "Lazos clientelares y bandos nobiliarios conquenses durante el siglo XV", Espacio, Tiempo y Forma. Serie III, Historia Medieval, 19 (2007), pp. 211-231.

- "Usurpaciones de términos y abusos señoriales en la jurisdicción urbana de Cuenca a finales de la Edad Media”, en Beatriz Arízaga Bolumburu y Jesús Ángel Solórzano Telechea (coords), La ciudad Medieval y su influencia territorial. Nájera. Encuentros internacionales del Medievo (Nájera, del 26 al 29 de julio de 2006), Logroño, 2007, pp. 221-238.

- "Por serviçios muchos e buenos que me ha fecho. Los criados de las casas nobiliarias conquenses en la Baja Edad Media", Anuario de Estudios Medievales, 39/2 (2009), pp. 703-721.

- "Ciudad, nobleza y frontera: el oficio concejil de guarda mayor en Cuenca y Huete durante el siglo XV", en Jesús Ángel Solórzano Telechea y Beatriz Arízaga Bolumburu, (eds.), La gobernanza de la ciudad europea en la Edad Media, Logroño, 2011, pp. 227-245.

Ortego Rico, Pablo, Poder financiero y gestión tributaria en Castilla: los agentes fiscales en Toledo y su reino (1429-1504), Madrid, 2016.

Palencia Herrejón, Juan Ramón, Los Ayala de Toledo: desarrollo e instrumentos de poder de un linaje nobiliario en el siglo XV, Toledo, 1995.

Paulino Montero, Elena, El patrocinio arquitectónico de los Velasco (1313-1512). Construcción y contexto de un linaje en la Corona de Castilla, tesis doctoral inédita leída en la Universidad Complutense de Madrid, Facultad de Geografía e Historia, Departamento de Historia del Arte I (Medieval), 2015-10-01.

Pereda Espeso, Felipe, "Mencía de Mendoza $(† 1500)$, mujer del I Condestable de Castilla", en Felipe Pereda, Begoña Alonso y María Cruz de Carlos, Patronos y coleccionistas. Los Condestables de Castilla y el arte (siglos XV-XVII), Vallado- 
lid, 2005, pp. 9-119.

- y Alfonso Rodríguez de Ceballos, "Coeli enarrant gloriam Dei. Arquitectura, iconografía y liturgia en la capilla de los Condestables de la Catedral de Burgos", Annali di Architettura, IX (1997), pp. 17-34.

Pereyra Alza, Osvaldo, El señorio de los Condestables de Castilla en el norte de España. Dominio, Patronazgo y Comunidades, tesis doctoral inédita leída en la Universidad de Santander, 2014-05-16.

Peribañez Otero, Jesús, Territorio, sociedad y conflictos en el tránsito hacia la modernidad. La Ribera del Duero burgalesa a finales de la Edad Media, tesis doctoral inédita leída en la Universidad de Valladolid, Facultad de Filosofía y Letras, Departamento de Historia Antigua y Medieval-Instituto Universitario de Historia Simancas, 2013.

Quintanilla Raso, María Concepción, "El dominio de las ciudades por la nobleza. El caso de Córdoba en la segunda mitad del siglo XV", En la España Medieval, 10 (1987), pp. 109-124.

- "Estructura y función de los bandos nobiliarios en Córdoba a fines de la Edad Media", en Bandos y querellas dinásticas en España al final de la Edad Media. Actas del Coloquio celebrado en la Biblioteca Española de París los días 15 y 16 de mayo de 1987, Madrid, 1991, pp. 157-176.

- "Principios y estrategias de la cultura nobiliaria. Redes de solidaridad, clientelismo y facciones en la Córdoba de fines del Medievo", en Córdoba, el Gran Capitán y su época, Córdoba, 2004, pp. 47-74.

Rucquoi, Adeline, Valladolid en la Edad Media, Valladolid, 1987, 2 vols.

Sánchez Benito, José María, "Territorio y conflicto en el ámbito jurisdiccional de Cuenca (época de los Reyes Católicos)", Espacio, Tiempo y Forma. Serie III, Historia Medieval, 9 (1996), pp. 89-118.

- "Nobleza territorial y política ciudadana en el siglo XV (los concejos del área del Tajo)", Espacio, Tiempo y Forma. Serie III, Historia Medieval, 27 (2014), pp. 463-502.

Sánchez Saus, Rafael, La nobleza andaluza en la Edad Media, Granada, 2005.

Solórzano Telechea, Jesús Ángel, Santander en la Edad Media. Patrimonio, parentesco y poder, Santander, 2002.

Tomás y Valiente, Francisco, "Origen bajomedieval de la patrimonialización y la enajenación de oficios públicos en Castilla", en Actas del Primer Symposium de la Historia de la Administración, Madrid, 1967. 